Foundations of Educational Technology 



\title{
Foundations of Educational Technology
}

\author{
PENNY THOMPSON
}

OKLAHOMA STATE UNIVERSITY LIBRARIES

STILLWATER, OKLAHOMA 


\section{() (1) (\$)}

Foundations of Educational Technology by Penny Thompson is licensed under a Creative Commons Attribution-NonCommercial 4.0 International License, except where otherwise noted. 


\section{Contents}

Chapter I: Introduction to Educational Technology

1.1 History and Influences on the Field 3

1.2 Chapter Summary $\quad 5$

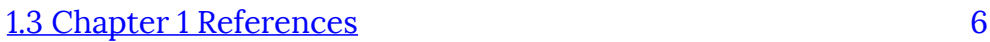

Chapter 2: Human Development

2.1 Cognitive Development: The Theory of Jean Piaget 9

2.2 Social Development: Erikson's Eight Psychosocial 18

Crises

2.3 Chapter Summary $\quad 25$

2.4 Chapter 2 References $\quad 26$

Chapter 3: Learning Theory

3.1 Behaviorist Theories of Learning 29

3.2 Cognitive Theories of Learning 35

3.3 Social Theories of Learning 41

3.4 Connectivism 44

3.5 Chapter Summary $\quad 45$

3.6 Chapter 3 References $\quad 46$

Chapter 4: Motivation

4.1 Goal Orientation 
4.2 Attribution Theory $\quad 54$

4.3 Self-Efficacy $\quad 58$

4.4 Self-Determination Theory 62

4.5 Expectancy-Value Theory $\quad 70$

4.6 Designing for Motivation $\quad 72$

4.7 Chapter Summary $\quad 73$

4.8 Chapter 4 References $\quad 74$

Chapter 5: Adult \& Workplace Learning

5.1 Andragogy $\quad 79$

5.2 Community of Practice $\quad 81$

5.3 Transformative Learning $\quad 82$

5.4 Chapter Summary $\quad 83$

5.5 Chapter 5 References $\quad 84$

Chapter 6: Communication

$\begin{array}{ll}\text { 6.1 Communication Models } & 87\end{array}$

6.2 Instructional Message Design $\quad 89$

6.3 Chapter Summary $\quad 91$

6.4 Chapter 6 References $\quad 92$

Chapter 7: Research in Educational Technology

7.1 Views of Knowledge $\quad 95$

$\begin{array}{ll}7.2 \text { Research Traditions } & 97\end{array}$

$\begin{array}{ll}7.3 \text { Constructivist Research } & 99\end{array}$

7.4 Chapter Summary 103

$\begin{array}{ll}7.5 \text { Chapter } 7 \text { References } & 105\end{array}$ 
Chapter 8: Instructional Design

8.1 Instructional Design Models $\quad 109$

8.2 Cultural Competence in Instructional Design 114

8.3 Careers in Instructional Design 116

8.4 Chapter Summary 118

$\begin{array}{ll}8.5 \text { Chapter } 8 \text { References } & 119\end{array}$

Chapter 9: Technology Selection and Integration

9.1 The "Media Debate" 123

9.2 Replace, Amplify, and Transform 125

9.3 TPACK 127

9.4 Chapter Summary 130

9.5 Chapter 9 References $\quad 131$

$\underline{\text { Chapter Io: Acceptance and Diffusion of Technology }}$

10.1 Technology Acceptance Model 135

10.2 Decomposed Theory of Planned Behavior 137

10.3 Diffusion of Innovation 138

10.4 Chapter Summary 141

10.5 Chapter 10 References 142

Chapter Ir: Professional Ethics

$\begin{array}{ll}11.1 \text { Copyright } & 147\end{array}$

11.2 Conflicts of Interest $\quad 148$

11.3 Academic Integrity $\quad 149$

11.4 Ethical Research 150

11.5 Chapter Summary $\quad 152$ 
$\underline{11.6 \text { Chapter } 11 \text { References }}$

Appendix 


\section{CHAPTER I: \\ INTRODUCTION TO \\ EDUCATIONAL TECHNOLOGY}

The current definition of Educational Technology, as defined by the Definition and Terminology Committee of the Association for Educational Communications and Technology (AECT) is "the study and ethical practice of facilitating learning and improving performance by creating, using, and managing appropriate technological processes and resources" (Januszewski \& Molenda, 2008, p. 1).

Januszewski \& Molenda (2008) further describe each of the major terms in the above definition as follows:

- Study - research and reflective practice in order to "examine the appropriate applications of processes and technologies to the improvement of learning" (p. 2).

- Ethical practice - ethics are not merely rules to follow, but the basis for our practice as educational technologists. We should question our assumptions and seek to serve the benefit of learners and of society.

- Facilitating - the focus in the field has shifted from its early focus on transferring knowledge from teacher to learner to a focus on facilitating activities and environments that engage the learner and lead to deep learning.

- Learning - the current conception of learning goes beyond mere retention of information to encompass "the acquisition of knowledge, skills, and attitudes used beyond the classroom walls" (p. 4). 
- Improving - educational technology should provide efficient and cost-effective ways to bring about the desired learning benefits.

- Performance - the "ability to use and apply the new capabilities gained" (p. 7).

- Creating - "the research, theory, and practice involved in the generation of instructional materials, learning environments, and large teaching learning systems in many different settings" (p. 7).

- Using - includes the selection of an appropriate resource as well as its implementation.

- Managing - can include project management and management of large-scale systems.

- Appropriate - suitable for the defined purpose, based on information and sound professional judgement

- Technological - processes and resources

- Process - " a series of activities directed towards a specific result"

(p. 11)

- Resources - "people, tools, technologies, and materials designed to help learners" (p. 12).

While this definition of terms may seem abstract, you can see that it encompasses much more than simply the use of the latest digital gadgets. Educational technology involves a thoughtful effort to employ the right technologies in the right way to meet learning goals. 


\section{I.I History and Influences on the Field}

According to Seels and Richey (1994), the educational technology field emerged, and continues to develop, through interactions of influences, including foundational research and theory and the features and capabilities of current technologies. This means the field of educational technology is "a child not only of theoretical knowledge, but also of practical knowledge" (p. 68).

Theory from fields as diverse as psychology, engineering, communications, computer science, business, and education has contributed foundational knowledge, while emerging new technologies prompt researchers to explore new possibilities for creating learning environments, and to further build and refine theory.

Reiser (2001) provided an extensive summary of the history of the field, tracing its roots back to the early 1900s. The first catalogue of instructional film was produced in the US in 1910, and a "visual instruction" movement, with professional organizations and journals dedicated to the topic, arose. This became known as "audiovisual instruction" as technology (e.g., film with sound) advanced. Film and other media were used extensively for military training during World War II (Seels \& Richey, 1994; Reiser, 2001), and scholars such as Edgar Dale (https://en.wikipedia.org/wiki/ Edgar Dale) contributed to theoretical discussions about how media might contribute to learning. Educational television was the focus of attention in the 1950s and 1960s, until the computer emerged as the next technology with potential to change education.

To see how technology tools and their use in education has evolved since the advent of computers, see the following three videos: 
- Very short - https://youtu.be/UFwWWsz X9s

An interactive or media element has been excluded from

㚇 this version of the text. You can view it online here:

https://open.library.okstate.edu/

foundationsofeducationaltechnology/?p=47

- Medium Length ( 8 minutes) - https://youtu.be/t5 v9Aqb9XA

An interactive or media element has been excluded from

믓 this version of the text. You can view it online here:

https://open.library.okstate.edu/

foundationsofeducationaltechnology/?p=47

- More detailed ( 14 minutes) - https://youtu.be/ jJejENZuybsText

An interactive or media element has been excluded from this version of the text. You can view it online here:

https://open.library.okstate.edu/

foundationsofeducationaltechnology/?p=47 


\section{I.2 Chapter Summary}

Although educational technology is still "young" compared to many other fields of study, it has a rich and diverse history. The subsequent chapters of this text review will introduce you to the various influences, theories, and traditions that inform this exciting field of study and practice. 


\section{I.3 Chapter i References}

Januszewski, A., \& Molenda, M. (2008). Educational technology: A definition with commentary. New York: Routledge.

Reiser, R. A. (2001). A History of Instructional Design and Technology: Part I: A History of Instructional Media. Educational Technology Research and Development, 49, 53-64.

Reiser, R. A. (2001). A History of Instructional Design and Technology: Part II: A History of Instructional Design. Educational Technology Research and Development, 49, 57-67.

Seels, B. B. \& Richey, R.C. (1994). Instructional technology: The definition and domains of the field. AECT: Bloomington, IN 


\section{CHAPTER 2: HUMAN DEVELOPMENT}

When integrating technology into the teaching and learning environment, it is vital to consider the developmental stage of the learner. This chapter reviews human development from both a cognitive perspective (based on the work of Piaget) and a social perspective (based on Erikson). It provides a foundation for later chapters that focus more explicitly on teaching and learning with technology. 



\section{I Cognitive Development: The Theory of Jean Piaget}

Cognition refers to thinking and memory processes, and cognitive development refers to long-term changes in these processes. One of the most widely known perspectives about cognitive development is the cognitive stage theory of a Swiss psychologist named Jean Piaget. Piaget created and studied an account of how children and youth gradually become able to think logically and scientifically.

Piaget believed that learning proceeded by the interplay of assimilation (adjusting new experiences to fit prior concepts) and accommodation (adjusting concepts to fit new experiences). The to-and-fro of these two processes leads not only to short-term learning, but also to long-term developmental change. The longterm developments are really the main focus of Piaget's cognitive theory.

After observing children closely, Piaget proposed that cognition developed through distinct stages from birth through the end of adolescence. By "stages" he meant a sequence of thinking patterns with four key features:

1. The stages always happen in the same order.

2. No stage is ever skipped.

3. Each stage is a significant transformation of the stage before it.

4. Each later stage incorporated the earlier stages into itself.

Basically, this is a "staircase" model of development. Piaget proposed four major stages of cognitive development, and called them (1) sensorimotor intelligence, (2) preoperational thinking, (3) concrete operational thinking, and (4) formal operational thinking. Each stage 
is correlated with an age period of childhood, but only approximately.

\section{The Sensorimotor Stage: Birth to Age 2}

In Piaget's theory, the sensorimotor stage occurs first, and is defined as the period when infants "think" by means of their senses and motor actions. As every new parent will attest, infants continually touch, manipulate, look, listen to, and even bite and chew objects. According to Piaget, these actions allow children to learn about the world and are crucial to their early cognitive development.

The infant's actions allow the child to represent (i.e., construct simple concepts of) objects and events. A toy animal may be just a confusing array of sensations at first, but by looking, feeling, and manipulating it repeatedly, the child gradually organizes her sensations and actions into a stable concept: toy animal. The representation acquires a permanence lacking in the individual experiences of the object, which are constantly changing. Because the representation is stable, the child "knows," or at least believes, that toy animal exists even if the actual toy animal is temporarily out of sight. Piaget called this sense of stability object permanence, a belief that objects exist whether or not they are actually present. Object permanence is a major achievement of sensorimotor development, and marks a qualitative transformation in how older infants ( 24 months) think about experience compared to younger infants ( $\sim 6$ months).

During much of infancy, of course, a child can only barely talk, so sensorimotor development initially happens without the support of language. It might therefore seem hard to know what infants are thinking. Piaget devised several simple, but clever, experiments to get around their lack of language, and these experiments suggest

10 | 2.1 Cognitive Development: The Theory of Jean Piaget 
that infants do indeed represent objects even without being able to talk (Piaget, 1952). In one, for example, he simply hid an object (like a toy animal) under a blanket. He found that doing so consistently prompts older infants (18-24 months) to search for the object, but fails to prompt younger infants (less than six months) to do so. (You can try this experiment yourself if you happen to have access to young infant.) Something motivates the search by the older infant even without the benefit of much language, and that "something" is presumed to be a permanent concept or representation of the object.

\section{The Preoperational Stage: Age 2 to 7}

In the preoperational stage, children use their new ability to represent objects in a wide variety of activities, but they do not yet do it in ways that are organized or fully logical. One of the most obvious examples of this kind of cognition is dramatic play, or the improvised make-believe of preschool children. If you have ever had responsibility for children of this age, you have likely witnessed such play.

Children engaged in imaginative activities are thinking on two levels at once-one imaginative and the other realistic. This dual processing of experience makes dramatic play an early example of metacognition, or reflecting on and the monitoring of thinking itself. Because metacognition is a highly desirable skill for success in school, teachers of young children (preschool, kindergarten, and even first or second grade) often make time and space in their classrooms for dramatic play, and sometimes even participate in it themselves to help develop the play further. 


\section{The Concrete Operational Stage: Age 7 to II}

As children continue into elementary school, they become able to represent ideas and events more flexibly and logically. Their rules of thinking still seem very basic by adult standards and usually operate unconsciously, but they allow children to solve problems more systematically than before, and therefore to be successful with many academic tasks. In the concrete operational stage, for example, a child may unconsciously follow the rule: "If nothing is added or taken away, then the amount of something stays the same."

This simple principle helps children understand certain arithmetic tasks (such as adding or subtracting zero from a number) as well as perform certain classroom science experiments (such as ones that involve calculating the combined volume of two separate liquids). Piaget called this period the concrete operational stage because children mentally "operate" on concrete objects and events. They are not yet able, however, to operate (or think) systematically about representations of objects or events. Manipulating representations is a more abstract skill that develops later, during adolescence.

Concrete operational thinking differs from preoperational thinking in two ways, each of which renders children more skilled as students. One difference is reversibility, or the ability to think about the steps of a process in any order. Imagine a simple science experiment, for example, such as one that explores why objects sink or float by having a child place an assortment of objects in a basin of water. Both the preoperational and concrete operational child can recall and describe the steps in this experiment, but only the concrete operational child can recall them in any order (e.g., chronological, reverse chronological, etc). This skill is very helpful for any task involving multiple steps-a common feature of tasks in the classroom. In teaching new vocabulary from a story, for another example, a teacher might tell students: "1) Every time you come across a word you don't know, write it down. 2) Then find and write 
down the definition of that word before returning to the story. 3) After you have a list of all the words you don't know, have a friend test you on your list." These directions involve repeatedly remembering to move back and forth between a second step and a first-a task that concrete operational students-and most adults-find easy, but that preoperational children often forget to do or find confusing. If the younger children are to do this task reliably, they may need external prompts, such as having the teacher remind them periodically to go back to the story to look for more unknown words.

The other new feature of thinking that develops during the concrete operational stage is the child's ability to decenter, or focus on more than one feature of a problem at a time. There are hints of decentration in preschool children's dramatic play, which requires being aware on two levels at once-knowing that a banana can be both a banana and a "telephone." But the decentration of the concrete operational stage is more deliberate and conscious than preschoolers' make-believe.

The other new feature of thinking that develops during the concrete operational stage is the child's ability to decenter, or focus on more than one feature of a problem at a time. There are hints of decentration in preschool children's dramatic play, which requires being aware on two levels at once-knowing that a banana can be both a banana and a "telephone." But the decentration of the concrete operational stage is more deliberate and conscious than preschoolers' make-believe. Now the child can attend to two things at once quite purposefully. Suppose you give students a sheet with an assortment of subtraction problems on it, and ask them to do this: "Find all of the problems that involve two-digit subtraction and that involve borrowing from the next column. Circle and solve only those problems." Following these instructions is quite possible for a concrete operational student (as long as they have been listening!) because the student can attend to the two subtasks simultaneously-finding the two-digit problems and identifying 
which actually involve borrowing. (Whether the student actually knows how to "borrow" however, is a separate question.)

In real classroom tasks, reversibility and decentration often happen together. A well-known example of joint presence is Piaget's experiments with conservation, the belief that an amount or quantity stays the same even if it changes apparent size or shape (Piaget, 2001; Matthews, 1998). Imagine two identical balls made of clay. Any child, whether preoperational or concrete operational, will agree that the two indeed have the same amount of clay in them simply because they look the same. But if you now squish one ball into a long, thin "hot dog," the preoperational child is likely to say that the amount of clay has changed-either because its shape is longer or because it is thinner, but at any rate because it now looks different. The concrete operational child will not make this mistake, thanks to new cognitive skills of reversibility and decentration: for him or her, the amount is the same because "you could squish it back into a ball again" (reversibility) and because "it may be longer, but it is also thinner" (decentration). Piaget would say the concrete operational child "has conservation of quantity."

Notice the difference between the two younger (preoperational) and the slightly older (concrete operational) child in this video as they perform the conservation task:

https://youtu.be/YtLEWVu815o (3:18 minutes).
固 An interactive or media element has been excluded from this version of the text. You can view it online here: https://open.library.okstate.edu/ foundationsofeducationaltechnology/?p=95

The classroom examples described above also involve reversibility 
and decentration. As already mentioned, the vocabulary activity described earlier requires reversibility (going back and forth between identifying words and looking up their meanings); but it can also be construed as an example of decentration (keeping in mind two tasks at once-word identification and dictionary search). And as mentioned, the arithmetic activity requires decentration (looking for problems that meet two criteria and also solving them), but it can also be construed as an example of reversibility (going back and forth between subtasks, as with the vocabulary activity). Either way, the development of concrete operational skills supports students in doing many basic academic tasks; in a sense, concrete operational skills make ordinary school work possible.

\section{The Formal Operational Stage: Age in and Beyond}

In the last of the Piagetian stages, the child becomes able to reason not only about tangible objects and events, but also about hypothetical or abstract ones. Hence, it has the name formal operational stage-the period when the individual can "operate" on "forms" or representations. With students at this level, the teacher can pose hypothetical (or contrary-to-fact) problems: "What if the world had never discovered oil?" or "What if the first European explorers had settled first in California instead of on the East Coast of the United States?" To answer such questions, students must use hypothetical reasoning, meaning that they must manipulate ideas that vary in several ways at once, and do so entirely in their minds.

Compare the child and the young woman in this video and notice the difference in their abilities to reason hypothetically:

https://youtu.be/YJyuy4B2aKU (1:02 minutes). 
An interactive or media element has been excluded from this version of the text. You can view it online here:

https://open.library.okstate.edu/

foundationsofeducationaltechnology/?p=95

The hypothetical reasoning that concerned Piaget primarily involved scientific problems. His studies of formal operational thinking therefore often look like problems that middle or high school teachers pose in science classes. In one problem, for example, a young person is presented with a simple pendulum, to which different amounts of weight can be hung (Inhelder \& Piaget, 1958). The experimenter asks: "What determines how fast the pendulum swings: the length of the string holding it, the weight attached to it, or the distance that it is pulled to the side?"

The young person is not allowed to solve this problem by trialand-error with the materials themselves, but must mentally reason a way to the solution. To do so systematically, he or she must imagine varying each factor separately, while also imagining the other factors that are held constant. This kind of thinking requires facility at manipulating mental representations of the relevant objects and actions-precisely the skill that defines formal operations.

As you might suspect, students with an ability to think hypothetically have an advantage in many kinds of school work: by definition, they require relatively few "props" to solve problems. In this sense they can in principle be more self-directed than students who rely only on concrete operations-certainly a desirable quality in the opinion of most teachers. Note, though, that formal operational thinking is desirable-but not sufficient for-solving all academic problems, and is far from being the only way that students achieve educational success. Formal thinking skills do not ensure

16 | 2.1 Cognitive Development: The Theory of Jean Piaget 
that a student is motivated or well-behaved, for example, nor does they guarantee other desirable skills, such as ability at sports, music, or art. The fourth stage in Piaget's theory is really about a particular kind of formal thinking: the kind needed to solve scientific problems and devise scientific experiments. Since many people do not normally deal with such problems in the normal course of their lives, it should be no surprise that research finds that many people never achieve or use formal thinking fully or consistently, or that they use it only in selected areas with which they are very familiar (Case \& Okomato, 1996). For teachers, the limitations of Piaget's ideas suggest a need for additional theories about development-ones that focus more directly on the social and interpersonal issues of childhood and adolescence. The next sections describe some of these. 


\subsection{Social Development: \\ Erikson's Eight Psychosocial}

Crises

Social development refers to the long-term changes in relationships and interactions involving self, peers, and family. It includes both positive changes, such as how friendships develop, and negative changes, such as aggression or bullying. One of the best-known theories of social development is the Eight Psychosocial Crises of Erik Erikson. Like Piaget, Erikson developed a theory of social development that relies on stages, except that Erikson thought of stages as a series of psychological or social (or psychosocial) crises -turning points in a person's relationships and feelings about themselves. Each crisis consists of a dilemma or choice that carries both advantages and risks, but in which one choice or alternative is normally considered more desirable or "healthy."

How one crisis is resolved affects how later crises are resolved. The resolution to each crisis also helps to create an individual's developing personality. Erikson proposed eight crises that extend from birth through old age. Four of the stages occur during the school years, and are given special attention here, but it is also helpful to know which crises are thought to come both before and after those in the school years.

Eight Psychosocial Crises According to Erikson 


\begin{tabular}{|c|c|c|}
\hline $\begin{array}{l}\text { Psychosocial } \\
\text { crisis }\end{array}$ & $\begin{array}{l}\text { Approximate } \\
\text { age }\end{array}$ & Description \\
\hline $\begin{array}{l}\text { Trust and } \\
\text { mistrust }\end{array}$ & $\begin{array}{l}\text { Birth to one } \\
\text { year }\end{array}$ & $\begin{array}{l}\text { Development of trust between caregiver } \\
\text { and child }\end{array}$ \\
\hline $\begin{array}{l}\text { Autonomy } \\
\text { and shame }\end{array}$ & Age 1-3 & $\begin{array}{l}\text { Development of control over bodily } \\
\text { functions and activities }\end{array}$ \\
\hline $\begin{array}{l}\text { Initiative and } \\
\text { guilt }\end{array}$ & Age 3-6 & $\begin{array}{l}\text { Testing limits of self-assertion and } \\
\text { purposefulness }\end{array}$ \\
\hline $\begin{array}{l}\text { Industry and } \\
\text { inferiority }\end{array}$ & Age 6-12 & $\begin{array}{l}\text { Development of sense of mastery and } \\
\text { competence }\end{array}$ \\
\hline $\begin{array}{l}\text { Identity and } \\
\text { role } \\
\text { confusion }\end{array}$ & Age 12-19 & $\begin{array}{l}\text { Development of identity and acknowledge } \\
\text { of identity by others }\end{array}$ \\
\hline $\begin{array}{l}\text { Intimacy and } \\
\text { isolation }\end{array}$ & Age 19-25+ & $\begin{array}{l}\text { Formation of intimate relationships and } \\
\text { commitments }\end{array}$ \\
\hline $\begin{array}{l}\text { Generativity } \\
\text { and } \\
\text { stagnation }\end{array}$ & Age $25-50+$ & $\begin{array}{l}\text { Development of creative or productive } \\
\text { activities that contribute to future } \\
\text { generations }\end{array}$ \\
\hline $\begin{array}{l}\text { Integrity and } \\
\text { despair }\end{array}$ & Age 50+ & $\begin{array}{l}\text { Acceptance of personal life history and } \\
\text { forgiveness of self and others }\end{array}$ \\
\hline
\end{tabular}

\section{Crises of Infants and Preschoolers: Trust, Autonomy, and Initiative}

Almost from the day they are born, infants face a crisis (in Erikson's sense) about trust and mistrust. They are happiest if they can eat, sleep, and excrete according to their own physiological schedules, regardless of whether their schedules are convenient for the caregiver. Unfortunately, though, a young infant is in no position to control or influence a caregivers scheduling needs, so the baby faces a dilemma about how much to trust or mistrust the caregiver's helpfulness. It is as if the baby asks, "If I demand food (or sleep, or a clean diaper, etc.) now, will my mother actually be able to help me meet this need?" Hopefully, between the two of them, caregiver and child resolve this choice in favor of the baby's trust: the caregiver 
proves to be at least "good enough" in attentiveness, and the baby risks trusting the caregiver's motivation and skill.

Almost as soon as this crisis is resolved, however, a new one develops over the issue of autonomy and shame. The child (who is now a toddler) may now trust his or her caregiver, but the very trust contributes to a desire to assert autonomy by taking care of basic personal needs, such as feeding, toileting, or dressing. Given the child's lack of experience in these activities, however, self-care is risky at first-the toddler may feed (or use the toilet, or dress themselves, etc.) clumsily and ineffectively. The child's caregiver, then, risks overprotecting the child and criticizing their early efforts unnecessarily, thus causing the child to feel shame for even trying. Hopefully, as with the earlier crisis of trust, the new crisis gets resolved in favor of autonomy through the combined efforts of the child to assert independence and of the caregiver to support the child's efforts.

Eventually, about the time a child is of preschool age, the autonomy exercised during the previous period becomes more elaborate, extended, and focused on objects and people other than the child and their basic physical needs. The child at a daycare center, for example, may now undertake to build the "biggest city in the world" out of all available unit blocks-even if other children want some of the blocks for themselves. The child's projects and desires create a new crisis of initiative and guilt, because the child soon realizes that acting on impulses or desires can sometimes have negative effects on others-more blocks for one child may mean fewer for someone else. As with the crisis over autonomy, caregivers have to support the child's initiatives whenever possible, but they must also take heed not to make the child feel guilty for desiring to have or to do something that affects others' welfare. By limiting behavior where necessary-but not limiting internal feelings-caregivers will be supporting the development of a lasting ability to take initiative. Expressed in Erikson's terms, the crisis is then resolved in favor of initiative. 
Even though only the last of these three crises overlaps with the school years, all three relate to issues faced by students of any age, and even by their teachers. A child or youth who is fundamentally mistrustful, for example, has a serious problem in coping with school life. If you are a student, it is essential for your long-term survival to believe that teachers and school officials have your best interests at heart, and that they are not imposing assignments or making rules gratuitously. Even though students are not infants any more, teachers function like Erikson's caregiving parents in that they need to prove worthy of students' trust through their initial flexibility and attentiveness.

Parallels from the classroom also exist for the crises of autonomy and of initiative. To learn effectively, students need to make choices and undertake academic initiatives at least some of the time, even though not every choice or initiative may be practical or desirable. Teachers, for their part, need to make true choices and initiatives possible, and refrain from criticizing, even accidentally, a choice or intention behind an initiative even if the teacher privately believes that it is "bound to fail." Support for choices and initiative should be focused on providing resources and on guiding the student's efforts toward more likely success. In these ways, teachers function like parents of toddlers and preschoolers in Erikson's theory of development, regardless of the age of their students.

\section{The Crisis of Childhood: Industry and Inferiority}

Once into elementary school, the child is faced for the first time with becoming competent and worthy in the eyes of the world at large, or more precisely in the eyes of classmates and teachers. To achieve their esteem, he or she must develop skills that require effort that is sustained and somewhat focused. The challenge creates the crisis of industry and inferiority. To be respected by teachers, for example, the child must learn to read and to behave 
like a "true student." To be respected by peers, he or she must learn to cooperate and to be friendly, among other things. There are risks involved in working on these skills and qualities, because there can be no guarantee of success with them in advance. If the child does succeed, therefore, he or she experiences the satisfaction of a job well done and of skills well learned-a feeling that Erikson called industry. If not, however, the child risks feeling lasting inferiority compared to others. Teachers therefore have a direct, explicit role in helping students to resolve this crisis in favor of industry or success.

They can set realistic academic goals for students-ones that tend to lead to success-and then provide materials and assistance for students to reach their goals. Teachers can also express their confidence that students can in fact meet their goals if and when the students get discouraged, and avoid hinting (even accidentally) that a student is simply a "loser." Paradoxically, these strategies will work best if the teacher is also tolerant of less-than-perfect performance by students. Too much emphasis on perfection can undermine some students' confidence-fostering what Erikson called inferiority-by making academic goals seem beyond reach.

\section{The Crisis of Adolescence: Identity and Role Confusion}

As children develop lasting talents and attitudes as a result of the crisis of industry, they begin to face a new question: what do all the talents and attitudes add up to be? Who is the "me" embedded in this profile of qualities? These questions are the crisis of identity and role confusion. Defining identity is riskier than it may appear, because some talents and attitudes may be poorly developed, and some may even be undesirable in the eyes of others. To further complicate the issue, some valuable talents and attitudes may evade 
others' notice. Conflicts in resolving the identify and role confusion crisis may yield a personal misunderstanding of one's attitudes and talents, or confusion regarding who others expect that person to be. In Erikson's terms, role confusion is the result.

Teachers can minimize role confusion in a number of ways. One is to offer students diverse role models by identifying models in students' reading materials, for example, or by inviting diverse guests to school. The point of these strategies would be to express a key idea: that there are many different ways to be respected, successful, and satisfied with life. Another way to support students' identity development is to be alert to students' confusions about their futures, and refer them to counselors or other services outside school that can help sort these out. Still another strategy is to tolerate changes in students' goals and priorities-e.g., sudden changes in extra-curricular activities or in personal plans after graduation. Since students are still "trying on" different roles, discouraging experimentation may not be in students' best interests.

\section{The Crises of Adulthood: Intimacy, Generativity, and Integrity}

Beyond the school years, according to Erikson, individuals continue psychosocial development by facing additional crises. Young adults, for example, face a crisis of intimacy and isolation. This crisis is about the risk of establishing close relationships with a select number of others. Whether the relationships are heterosexual, homosexual, or not sexual at all, their defining qualities are depth and sustainability. Without them, an individual risks feeling isolated.

Assuming that a person resolves this crisis in favor of intimacy, however, he or she then faces a crisis about generativity and stagnation. This crisis is characteristic of most of adulthood, and not 
surprisingly therefore is about caring for or making a contribution to society, and especially to its younger generations. Generativity is about making life productive and creative so that it matters to others. One obvious way for some to achieve this feeling is by raising children, but there are also many other ways to contribute to the welfare of others. 


\subsection{Chapter Summary}

While the approaches taken by Piaget and Erikson are not the only ways to look at development, they offer valuable insights into how learners approach tasks and relationships in a learning environment. While Piaget focused on cognitive development, Erikson provided perspective on how learning and development occur within a larger social context. The next chapter will explore theories specifically targeted to learning. 


\subsection{Chapter 2 References}

Case, R. \& Okamoto, Y. (1996). The role of central conceptual structures in children's thought. Chicago:

Society for Research on Child Development.

Inhelder, B. \& Piaget, J. (1958). The growth of logical thinking from childhood to adolescence: An essay on the growth of formal operational structures. New York: Basic Books.

Matthews, G. (1998). The philosophy of childhood. Cambridge, MA: Harvard University Press.

Piaget, J. (1952). The origins of intelligence in children. New York: International Universities Press.

Piaget, J. (2001). The psychology of intelligence. Oxford, UK: Routledge.

A large portion of the text in this chapter is taken from Chapter 3 of the open access text Educational Psychology, 3rd Edition, 2011 by Kelvin Seiffert and Rosemary Sutton. (Minor modifications to words and phrases were made as needed to fit the current context.) 


\section{CHAPTER 3: LEARNING THEORY}

In order to make good decisions about how to integrate technology into teaching and learning environments, it is crucial to understand what is known about how learning happens. This is a tall order because the human mind is complex and researchers disagree on what learning is and how to measure it. Thus, there are several theories about learning, each appearing to explain some aspects of learning better than others. This chapter introduces behaviorist, cognitive, and social theories of learning. In addition, the digital-age connectivist theory is briefly discussed. (Adult learning theories are discussed in Chapter 5 of this text.) 



\section{I Behaviorist Theories of Learning}

In the early 1900s, the most prevalent way of looking at learning was the view we call behaviorism. Behaviorists defined learning as an observable change in behavior. At the time, this was viewed as a scientific approach, in contrast to the introspective or psychoanalytic view of learning that had been prevalent in the past. Behaviorists believed that we can never know what is going on "inside people's heads" and that it is inappropriate to try to guess or speculate at what cannot be empirically observed. Instead, they believed that we should watch for observable changes in behavior to find out what people were learning.

\section{Classical Conditioning}

In the early part of the 20th century, Russian physiologist Ivan Pavlov (1849-1936) was studying the digestive system of dogs when he noticed an interesting behavioral phenomenon: The dogs began to salivate when the lab technicians who normally fed them entered the room, even though the dogs had not yet received any food. Pavlov realized that the dogs were salivating because they knew they were about to be fed; the dogs had begun to associate the arrival of the technicians with the food that soon followed their appearance in the room.

With his team of researchers, Pavlov began studying this process in more detail. He conducted a series of experiments in which, over a number of trials, dogs were exposed to a sound immediately before receiving food. He systematically controlled the onset of the sound and the timing of the delivery of the food, and recorded the amount 
of the dogs' salivation. Initially the dogs salivated only when they saw or smelled the food, but after several pairings of the sound and the food, the dogs began to salivate as soon as they heard the sound. Pavlov concluded that the animals had learned to associate the sound with the food that followed.

Pavlov had identified a fundamental associative learning process called classical conditioning. Classical conditioning refers to learning that occurs when a neutral stimulus (e.g., a tone) becomes associated with a stimulus (e.g., food) that naturally produces a behavior (e.g., salivation). After the association is learned, the previously neutral stimulus (e.g., a tone) is by itself sufficient to produce the behavior (e.g., salivation).

Psychologists use specific terms to identify the stimuli and the responses in classical conditioning. The unconditioned stimulus (US) is something (such as food) that triggers a natural occurring response, and the unconditioned response (UR) is the naturally occurring response (such as salivation) that follows the unconditioned stimulus. The conditioned stimulus (CS) is a neutral stimulus that, after being repeatedly presented prior to the unconditioned stimulus, evokes a similar response as the unconditioned stimulus. In Pavlov's experiment, the sound of the tone served as the conditioned stimulus that, after learning, produced the conditioned response (CR), which is the acquired response to the formerly neutral stimulus. Note that the UR and the $\mathrm{CR}$ are the same behavior-in this case salivation-but they are given different names because they are produced by different stimuli (the US and the CS, respectively). 


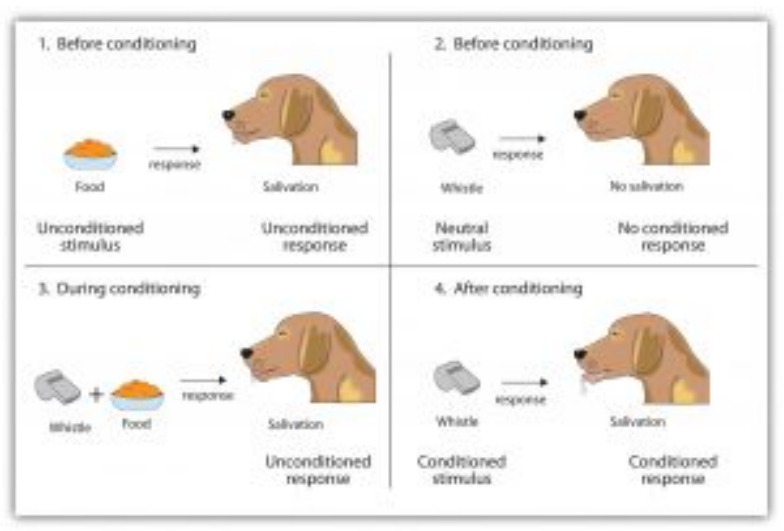

The image found at https://goo.gl/images/u4HSU3 is helpful for visualizing these relationships.

Conditioning is evolutionarily beneficial because it allows organisms to develop expectations that help them prepare for both good and bad events. Imagine, for instance, that an animal first smells a new food, eats it, and then gets sick. If the animal can learn to associate the smell (CS) with the food (US), then it will quickly learn that the food creates the negative outcome, and not eat it the next time.

\section{Operant Conditioning}

In contrast to classical conditioning, which involves involuntary responses (e.g., salivating), B.F. Skinner's Operant Conditioning, posited that learning occurrs through the process of reinforcing an appropriate voluntary response to a stimulus in the environment.

Operant Conditioning has some very specific terminology. This terminology is often misused because the terms have a different meaning from their common colloquial use. Skinner claimed that 
the consequences that follow any given behavior could either increase or decrease that behavior. He used the term reinforcement to describe consequences that increases a behavior and punishment to describe those that decrease the behavior. He further claimed that a reinforcement or punishment could be either a stimulus added, which he defined as positive, or or a stimulus removed, which he called negative. It is important to set aside the common meanings and connotations of the words positive and negative and focus on how they are defined in Operant Conditioning. In this context the terms are more like "adding and subtracting" rather than "good and bad."

A reinforcement, then, can be either positive or negative. For example, if you give a child praise for completing her homework (because you want her to continue this desirable behavior), you would be giving her positive reinforcement. Negative reinforcement, on the other hand, removes a consequence or stimulus that the person doesn't like, in the hope of increasing the desirable behavior. If you tell the child that because she completed her homework immediately after school today she is excused from helping with the dinner dishes, you are giving her negative reinforcement. In both cases, you are hoping the reinforcement you provide will increase the desirable behavior of completing her homework.

The goal of punishment is to decrease a behavior. Positive punishment is an added stimulus designed to decrease a behavior. If a child is acting out in class and you scold him, you are delivering a positive punishment. The scolding is an added stimulus. A negative punishment would be taking something away that the child wants. For example, if you tell him he has to stay in from recess after acting out in class, you are using negative punishment.

The important thing to remember about reinforcement and punishment is that the result determines whether a stimulus serves as a reinforcement or a punishment, regardless of the intentions 
of the person delivering the stimulus. A teacher can take a certain action with the intention of punishing a child, but end up inadvertently providing reinforcement. If the child who is acting out in class craves any kind of attention she can get from an adult, both the praise and the scolding can be equally reinforcing for her.

While the examples above involve humans, it is important to note that Skinner's research was primarily done with animals trained in special cages called "Skinner Boxes" designed to deliver reinforcements and punishments. For example, he would train a rat to push a lever when a green light came on by first watching the rat move around and explore the cage until it eventually pushed the lever. When the rat pushed the lever a food pellet would be released, which caused the rat to push the lever frequently. Once this behavior was established, he would start turning on a light, and only release a food pellet if the rat pushed the lever when the light was on. Eventually, the rat would be trained to push the lever every time the light came on.

Skinner believed that human learning occured by the same mechanism, and that even very complex behaviors could be learned by reinforcing intermediate behaviors (as in the example of the rat above) and gradually shaping the complex behavior. In 1957, Skinner published "Verbal Behavior," where he applied his theory to language learning. This was controversial. The linguist Noam Chomsky, for example, argued that Operant Conditioning was inadequate to explain how humans learn to construct new sentences in response to new experience.

For more information about B. F. Skinner and his Operant Conditioning theory, see this video: 
固 An interactive or media element has been excluded from this version of the text. You can view it online here:

https://open.library.okstate.edu/

foundationsofeducationaltechnology/?p=122

https://www.youtube.com/watch?v=D-RS80DVvrg (4:45 minutes).

\section{Behaviorism in Educational Technology}

Today, principles of Operant Conditioning are used by teachers for general classroom management and to support students with special needs. Educational technology has also employed Behaviorist principles, especially Operant Conditioning. Programmed Instruction (see https://en.wikipedia.org/wiki/ Programmed_learning), for example, is a teaching strategy that developed and grew along with advances in technology. Drill and practice software is helpful for specific content, such as multiplication tables or second language vocabulary, that must be learned to a level of automaticity. Games and gamification also make use of Operant Conditioning principles. Acquiring resources and "leveling up" provide reinforcement, while losing one's sword in a battle or falling off a cliff serve to punish errors. 


\subsection{Cognitive Theories of Learning}

In the 1960s, cognitive theories of learning gradually began to replace Behaviorism as a predominant view. Cognitive theorists claim that observable behaviors are not sufficient to describe learning because the internal thought processes are also part of learning. The cognitive perspective was heavily influenced by the development of computer technology and telecommunications, and use the computer as a metaphor to understand what is happening in the human mind. Learning is defined as storing and organizing information and concepts in the mind.

\section{Information Processing}

One of the early cognitive theories of learning and memory was Atkinson and Schiffrin's (1968) Information Processing Theory. This theory views the mind as a computer that accepts inputs and performs processing activities on those inputs, similar to the way a computer processes data. In this view there are three "buckets" known as memory stores.

When you take in information-seeing, hearing, smelling, etc.-it starts in the sensory register. You are constantly bombarded with sensory information, and most of these stimuli are dropped after reaching the sensory register because you don't pay attention to them. For example, when you are enjoying a meal in a restaurant with friends, the sound of other people's conversations reaches your ears, but you normally do not attend to these sounds and therefore do not remember hearing them. The stimuli that you do attend to are then sent to your short-term memory. The short-term memory 
is where you work with information, process it, and try to pass it into long-term memory.

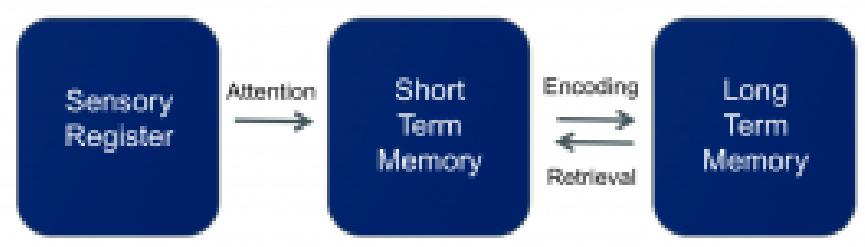

The theoretical terminology of Information Processing has worked its way into colloquial speech and somewhat changed in meaning. In Information Processing Theory, short-term memory is very short indeed-about 30 seconds! In order to keep something in your mind longer than that, you need to process that information. You do this by rehearsing (repeating) it, or connecting it to what you already know. Or, perhaps you create visual images. The processing you do to make the new information meaningful and memorable is called encoding. Encoding moves information from your short-term memory to your long-term memory.

When you need to remember something that you learned previously, you retrieve it from your long-term memory and move it back into your short-term memory, a process analogous to opening a file on your computer and displaying it on the desktop. This is why short-term memory is also known as working memory. (These two terms originated from different but similar theoretical models of how memory works.)

Short-term memory has a limited capacity. In his article "The Magical Number Seven," Miller (1956) proposed that we can hold 
approximately seven items in our short term memory, or, taking individual variation into account, "seven plus or minus two." There are strategies we use to help us effectively increase this capacity, however. Chunking is the process of memorizing small units so they become single items in memory. We can then hold seven plus or minus two "chunks" in our memory. An example of this would be a 10-digit phone number, which is chunked into an area code, prefix, and a final chunk of four digits. (This was more important in the days before mobile phones did our dialing for us!)

In contrast to our limited short-term memory, long-term memory is believed to be unlimited in capacity. While there is some disagreement about whether we really retain everything in long term-memory "forever," there is agreement that we retain a large amount of information for a very long time. Often when we have trouble remembering something, the difficulty is with retrieval. Retrieval is particularly difficult for things we memorize only by rote rehearsal; a more elaborate encoding process will lead to more useful retrieval cues.

\section{Cognitive Load Theory}

Cognitive Load Theory (Sweller, 1994) elaborates on the concept of a limited short term memory by defining three types of "load" that need to be considered by instructors and instructional designers. Extraneous load is the cognitive burden posed by distracting elements. An example would be a confusing navigation process in a poorly designed tutorial. Intrinsic load is the complexity inherent in the subject matter. Dealing with that complexity is part of learning the material, and can't be entirely avoided. Germane load is the cognitive demand of processing the subject matter. Remember that to move new information from short-term memory to long-term memory in a retrievable manner, we need to use elaboration techniques. Elaboration is effortful, however, and poses germane 
cognitive load. According to Cognitive Load Theory, instructors and instructional designers should seek to minimize extraneous cognitive load to free the learner's capacity to handle the intrinsic and germane load.

\section{Cognitive Theory of Multimedia Learning}

Richard Mayer's Cognitive Theory of Multimedia Learning is a particularly useful theory for educational technologists because it attempts to offer some prescriptive advice for designing media for learning. Let's use multimedia to explore this multimedia theory! Watch the following videos for more information:

- https://youtu.be/0aq2P0DZqEI (a very good explanation of the theory; 5:24 minutes)

https://open.library.okstate.edu/

foundationsofeducationaltechnology/?p=124

An interactive or media element has been excluded from this version of the text. You can view it online here:

https://open.library.okstate.edu/

foundationsofeducationaltechnology/?p=124 
- https://youtu.be/hw2hi7D1ALE (description of the theory and its implications; 5:27 minutes)

\section{An interactive or media element has been excluded from \\ 믓 this version of the text. You can view it online here:}

https://open.library.okstate.edu/

foundationsofeducationaltechnology/?p=124

- https://youtu.be/6XYSquPlr8U (an excellent and thorough explication: 13:03 minutes)

You can also read more about this theory here: https://www.eduhk.hk/apfslt/v12 issue2/rias/page4.htm.

\section{Constructivism}

Constructivists believe that learning occurs as an individual interacts with the environment and constructs meaning by making sense of his or her experience. While still a cognitivist theory, it emphasizes meaning-making processes that may be unique for each learner. The teacher's role is to create experiences that facilitate this meaning-making process.

Jonassen, Peck, \& Wilson (1999) define the following five attributes of meaningful learning:

- Learning is active. Learners manipulate the environment and learn from observing the natural consequences of their actions. 
- Learning is constructive. Learners integrate new experience with prior knowledge to construct meaning.

- Learning is intentional. Learners articulate learning goals and reflect on the progress towards these goals.

- Learning is authentic. Learners need to experience a rich, authentic context for their meaning-making.

- Learning is cooperative. Learners construct knowledge through productive conversation with other learners.

Educational technology can facilitate a constructivist learning experience through tools such as collaborative shared documents (e.g., wikis), information for exploration (e.g., web searching), complex simulations, and constructive projects (e.g., video creation). 


\subsection{Social Theories of Learning}

Behaviorist and cognitive theories of learning focus on the individual learner. Social learning theorists view learning as a process of adopting ways of thinking from the culture and community. Therefore, social interaction is a crucial part of the learning process. Two leading thinkers in the social learning tradition were Albert Bandura and Lev Vygotsky.

\section{Observational Learning (Albert Bandura)}

Observational learning is based on behaviorist principles, but is focused modeling-learning by observing the behavior of others. To demonstrate the importance of observational learning in children, Bandura, Ross, and Ross (1963) showed children a live image of either a man or a woman interacting with a Bobo doll, a filmed version of the same events, or a cartoon version of the events. As you can see in the video linked below, the Bobo doll is an inflatable balloon with a weight in the bottom that makes it bob back up when you knock it down. In all three conditions, the model violently punched, kicked, sat on, and hit the doll with a hammer:

\footnotetext{
An interactive or media element has been excluded from this version of the text. You can view it online here:

https://open.library.okstate.edu/

foundationsofeducationaltechnology/?p=128
} 
https://youtu.be/Pr0OTCVtHbU (4:08 minutes).

Take a moment to see how Albert Bandura explains his research into the modeling of aggression in children. The researchers first let the children view one of the three types of modeling, and then let them play in a room in which there were some toys. To create some frustration in the children, Bandura let the children play with the fun toys for only a couple of minutes before taking them away. Then Bandura gave the children a chance to play with the Bobo doll.

If you guessed that most of the children imitated the model, you would be correct. Regardless of which type of modeling the children had seen, and regardless of the sex of the model or the child, the children who had seen the model behaved aggressively, just as the model had done. They also punched, kicked, sat on the doll, and hit it with the hammer. Bandura and his colleagues had demonstrated that these children learned new behaviors simply by observing and imitating others.

Observational learning is useful for animals and for people because it allows us to learn without having to actually engage in what might be a risky behavior. Although modeling is normally adaptive, it can be problematic for children who grow up in violent families. These children are not only the victims of aggression, but they also see it happening to their parents and siblings. Because children learn how to be parents in large part by modeling the actions of their own parents, it is no surprise that there is a strong correlation between family violence in childhood and violence as an adult. Observational learning is also the basis for concern about the effect violent television shows and video games may have on children.

\section{Vygotsky's Social Learning Theory}

Lev Vygotsky developed and published his theory in Russia in the 
1920s, but it wasn't until the 1960s and early 1970s that his work became well-known among education researchers in the United States. His work emphasized learning through social interaction. Vygotsky believed that our culture provides us with "cognitive tools" that affect the way we think. Our language, for example, is a cultural tool. While language serves a similar function in all cultures, the unique features of a language can influence how we think. For example, if you are a speaker of a language that has different forms of address depending on social position (such as vous versus tu in French), you probably have a slightly different way of thinking about status and social position than a speaker of a language (such as English) that does not recognize this distinction. Similarly, children who learn to add and subtract with an abacus think about numbers differently than children who learn with different manipulatives or with only pencil and paper.

According to Vygotsky, children learn these cultural tools by interacting with adults, who model use of the tools and assist children in using them. Children begin by imitating the adults' behavior, but eventually they internalize them. The adult serves as a more knowledgeable other who provides scaffolding that allows the child to perform in his or her zone of proximal development (ZPD). The ZPD is the gap between what the child can do successfully without help and what he or she can do with help. The assistance provided is called scaffolding because it is intended to support the child temporarily and be gradually taken away as the child gains skill. (More advanced peers can also provide scaffolding.)

For more detail on Vygotsky's theory, see: http://epltt.coe.uga.edu/ index.php?title=Vygotsky\%27s constructivism. 


\subsection{Connectivism}

While behaviorists and cognitivists focused on the individual learning and social learning theories looked at learning within social systems, George Siemans (2005) believed that learning and knowledge could exist outside the person in a complex web of people and information sources. According to Sieman's (2005) Connectivist Theory, the following principles apply to learning:

- "Learning and knowledge rests in diversity of opinions.

- Learning is a process of connecting specialized nodes or information sources.

- Learning may reside in non-human appliances.

- Capacity to know more is more critical than what is currently known.

- Nurturing and maintaining connections is needed to facilitate continual learning.

- Ability to see connections between fields, ideas, and concepts is a core skill.

- Currency (accurate, up-to-date knowledge) is the intent of all connectivist learning activities.

Decision-making is itself a learning process. Choosing what to learn and the meaning of incoming information is seen through the lens of a shifting reality. While there is a right answer now, it may be wrong tomorrow due to alterations in the information climate affecting the decision" (Siemans, 2005, online).

You can read Siemans' complete article introducing Connectivism here: http://www.itdl.org/journal/jan 05/article01.htm. 


\subsection{Chapter Summary}

As you can see, understanding how people learn is an ongoing process. While the early behaviorists focused on observable behaviors, researchers are constantly seeking new ways to gain a better understanding of how learning happens. Sometimes, as in the cases of cognitive theories and connectivism, a new technology inspires new models and metaphors. Other times it is interaction with other cultures that influences theory, as when Vygotsky's work was translated into English. All of these theories and perspectives add to our understanding of teaching and learning. However, there are personal factors that influence how receptive we are to learning as well. In the next chapter we will discuss how motivation can affect readiness to learn. 


\subsection{Chapter 3 References}

Atkinson, R. C., \& Shiflrin, R. M. (1968). Human memory: A proposed system and its control processes. Psychology of Learning and Motivation, 2(1), 89-195.

Bandura, A., Ross, D., \& Ross, S. A. (1963). Imitation of film-mediated aggressive models. The Journal of Abnormal and Social Psychology, 66(1), 3-11.

Jonassen, D., Peck, K. L., \& Wilson, B. G. (1999). Technologies for meaning making. Learning with technology: A constructivist perspective (pp. 1 - 18). Columbus, OH: Prentice Hall.

Miller, G. A. (1956). The magical number seven, plus or minus two: Some limits on our capacity for processing information. Psychological Review, 63(2), 81.

Siemans, G. (2005). Connectivism: A learning theory for the digital age. International Journal of Instructional Technology and Distance Learning 2(1). Retrieved from http://www.itdl.org/ journal/jan_05/index.htm.

Sweller, J. (1994). Cognitive Load Theory, learning difficulty, and instructional design. Learning and Instruction, 4(4), 295-312.

The sections on classical conditioning and observational learning in this chapter were taken from Chapter 7 of the open access textbook Introduction to Psychology, published by the University of Minnesota in 2015. This text was itself adapted from a 2010 book published by an author who requested no attribution. 


\section{CHAPTER 4: MOTIVATION}

Think of an activity you do regularly that you love. Why do you do it? How hard do you work at it, and why? Now think of an activity you don't like so much. Why do you do it, and how hard do you work at it? Are there differences between the activities you love and those you dislike, in terms of your reasons for doing them, the effort you put into them, or the results and satisfaction you receive?

Motivation can be defined as "a theoretical construct used to explain the initiation, direction, intensity, persistence, and quality of behavior" (Brophy, 2004, p. 3). Or more simply, the reasons a person engages in a given behavior. It is important for educational technologists to understand and consider motivation when designing learning experiences for students.

There are several theories of motivation that each describe different aspects of the concept and that contribute to our understanding of it in different ways. This chapter briefly introduces the major theories of goal-orientation, expectancy-value, and selfdetermination theory. 



\section{I Goal Orientation}

One way motives vary is by the kind of goals that students set for themselves, and by how these goals support students' academic achievement. As you might suspect, some goals encourage academic achievement more than others, but even motives that do not concern academics explicitly tend to affect learning indirectly.

\section{Goals that Contribute to Achievement}

What kinds of achievement goals do students hold? Imagine three individuals-Maria, Sara, and Lindsay-who are taking algebra together. Maria's main concern is to learn the material as well as possible because she finds it interesting and because she believes it will be useful to her in later courses, perhaps at university. Hers is a mastery goal because she wants primarily to learn or master the material. Sara, however, is concerned less about algebra than about getting top marks on the exams and in the course. Hers is a performance goal because she is focused primarily on looking successful; learning algebra is merely a vehicle for performing well in the eyes of peers and teachers. Lindsay, for her part, is primarily concerned about avoiding a poor or failing mark. Hers is a performance-avoidance goal, or failure-avoidance goal, because she is not really concerned about learning algebra, as Maria is, or about competitive success, as Sara is; she is simply intending to avoid failure.

As you might imagine, mastery, performance, and performanceavoidance goals often are not experienced in pure form, but in combinations. If you play the clarinet in the school band, you might want to improve your technique simply because you enjoy playing as well as possible-essentially a mastery orientation. But you might 
also want to look talented in the eyes of classmates-a performance orientation. Another part of what you may wish, at least privately, is to avoid looking like a complete failure at playing the clarinet. One of these motives may predominate over the others, but they all may be present.

Mastery goals tend to be associated with enjoyment of learning the material at hand, and in this sense represent an outcome that teachers often seek for students. By definition therefore they are a form of intrinsic motivation. As such, mastery goals have been found to be better than performance goals at sustaining students' interest in a subject. In one review of research about learning goals, for example, students with primarily mastery orientations toward a course they were taking not only tended to express greater interest in the course, but also continued to express interest well beyond the official end of the course, and to enroll in further courses in the same subject (Harackiewicz, et al., 2002; Wolters, 2004).

Performance goals, on the other hand, imply extrinsic motivation, and tend to show the mixed effects of this orientation. A positive effect is that students with a performance orientation do tend to get higher grades than those who express primarily a mastery orientation. The advantage in grades occurs both in the short term (with individual assignments) and in the long term (with overall grade point average when graduating). But there is evidence that performance oriented students do not actually learn material as deeply or permanently as students who are more mastery oriented (Midgley, Kaplan, \& Middleton, 2001). A possible reason is that measures of performance-such as test scores-often reward relatively shallow memorization of information and therefore guide performance-oriented students away from processing the information thoughtfully or deeply. Another possible reason is that a performance orientation, by focusing on gaining recognition as the best among peers, encourages competition among peers. Giving 
and receiving help from classmates is thus not in the self-interest of a performance-oriented student, and the resulting isolation limits the student's learning.

\section{Goals that Indirectly Affect Achievement}

\section{Failure-Avoidant Goals}

Failure-avoidant goals by nature undermine academic achievement. Often they are a negative byproduct of the competitiveness of performance goals (Urdan, 2004). If a teacher (and sometimes also fellow students) puts too much emphasis on being the best in the class, and if interest in learning the material as such therefore suffers, then some students may decide that success is beyond their reach or may not be desirable in any case. The alternative-simply avoiding failure-may seem wiser as well as more feasible. Once a student adopts this attitude, he or she may underachieve more or less deliberately, doing only the minimum work necessary to avoid looking foolish or to avoid serious conflict with the teacher. Avoiding failure in this way is an example of self-handicapping-or making deliberate actions and choices that reduce a student's chances of success. Students may self-handicap in a number of ways; in addition to not working hard, they may procrastinate about completing assignments, for example, or set goals that are unrealistically high.

\section{Social Goals}

Most students need and value relationships, both with classmates and with teachers, and often (though not always) they get a good deal of positive support from the relationships. But the effects of 
social relationships are complex, and at times can work both for and against academic achievement. If a relationship with the teacher is important and reasonably positive, then the student is likely to try pleasing the teacher by working hard on assignments (Dowson \& McInerney, 2003). Note, though, that this effect is closer to performance than mastery; the student is primarily concerned about looking good to someone else. If, on the other hand, a student is especially concerned about relationships with peers, the effects on achievement depend on the student's motives for the relationship, as well as on peers' attitudes. Desiring to be close to peers personally may lead a student to ask for help, and give help to peers-behaviors that may support higher achievement, at least up to a point. But desiring to impress peers with skills and knowledge may lead to the opposite; as already mentioned, the competitive edge of such a performance orientation may keep the student from collaborating and, in this indirect way, reduce a student's opportunities to learn. The abilities and achievement motivation of peers themselves can also make a difference, but once again the effects vary depending on the context. Low achievement and motivation by peers affect an individual's academic motivation more in elementary school than in high school, more in learning mathematics than learning to read, and more if there is a wide range of abilities in a classroom than if there is a more narrow range (Burke \& Sass, 2006). In spite of these complexities, social relationships are valued so highly by most students that teachers should generally facilitate them, while also keeping an eye on their nature and their consequent effects on achievement.

\section{Encouraging Mastery Goals}

Even though a degree of performance orientation may be inevitable in school because of the mere presence of classmates, it does not have to take over students' academic motivation completely. 
Teachers can encourage mastery goals in various ways. One way is to allow students to choose specific tasks or assignments for themselves, when possible, because their choices are more likely than usual to reflect prior personal interests, and hence be more intrinsically motivated. The limitation of this strategy, of course, is that students may not see some of the connections between their prior interests and the curriculum topics at hand. In this case it also helps for the teacher to look for and point out the relevance of current topics or skills to students' personal interests and goals. Suppose, for example, that a student enjoys the latest styles of music. This interest may actually have connections with a wide range of school curriculum, such as:

- Biology (because of the physiology of the ear and of hearing)

- Physics or general science (because of the nature of musical acoustics)

- History (because of changes in musical styles over time)

- English (because of relationships of musical lyrics and themes with literary themes)

- Foreign languages (because of comparisons of music and songs among cultures)

Still another way to encourage mastery orientation is to focus on students' individual effort and improvement as much as possible, rather than on comparing students' successes to each other. You can encourage this orientation by giving students detailed feedback about how they can improve performance, or by arranging for students to collaborate on specific tasks and projects rather than to compete about them, and in general by showing your own enthusiasm for the subject at hand. 


\subsection{Attribution Theory}

Attributions are perceptions about the causes of success and failure. Suppose that you get a low mark on a test and are wondering what caused the low mark. You can construct various explanations for (that is, make various attributions about) this failure: maybe you did not study very hard; maybe the test itself was difficult; maybe you were unlucky; maybe you doubt your own intelligence. Each explanation attributes the failure to a different factor. The explanations that you settle upon may reflect the truth accurately, or then again, they may not. What is important about attributions is that they reflect personal beliefs about the sources or causes of success and failure. As such, they tend to affect motivation in various ways, depending on the nature of the attribution (Weiner, 2005).

\section{Locus, Stability, and Controllability}

Attributions vary in three underlying ways: locus, stability, and controllability. The locus of an attribution is the location (figuratively speaking) of the source of success or failure. If you attribute a top mark on a test to your ability, then the locus is internal; if you attribute the mark to the test's having easy questions, then the locus is external. The stability of an attribution is its relative permanence. If you attribute the mark to your ability, then the source of success is relatively stable - by definition, ability is a relatively lasting quality. If you attribute a top mark to the effort you put into studying, then the source of success is unstable effort can vary and has to be renewed on each occasion or else it disappears. The controllability of an attribution is the extent to which the individual can influence it. If you attribute a top mark to your effort at studying, then the source of success is relatively 
controllable-you can influence effort simply by deciding how much to study. But if you attribute the mark to simple luck, then the source of the success is uncontrollable-there is nothing that can influence random chance.

As you might suspect, the way that these attributions combine affects students' academic motivations in major ways. It usually helps both motivation and achievement if a student attributes academic successes and failures to factors that are internal and controllable, such as effort or a choice to use particular learning strategies (Dweck, 2000). Attributing successes to factors that are internal but stable or uncontrollable (like ability), on the other hand, is both a blessing and a curse: sometimes it can create optimism about prospects for future success ("I always do well"), but it can also lead to indifference about correcting mistakes (Dweck, 2006), or even create pessimism if a student happens not to perform at the accustomed level ("Maybe I'm not as smart as I thought"). Worst of all for academic motivation are attributions, whether stable or not, related to external factors. Believing that performance depends simply on luck ("The teacher was in a bad mood when marking") or on excessive difficulty of material removes incentive for a student to invest in learning. All in all, then, it seems important for teachers to encourage internal, controllable attributions about success.

\section{Influencing Students' Attributions}

One way or another, effective learning strategies involve framing teachers' own explanations of success and failure around internal, controllable factors. Instead of telling a student: "Good work! You're smart!", try saying: "Good work! Your effort really made a difference, didn't it?" If a student fails, instead of saying, "Too bad! This material is just too hard for you," try saying, "Let's find a strategy for practicing this more, and then you can try again." In both cases the first option emphasizes uncontrollable factors (innate intelligence, 
difficulty level), and the second option emphasizes internal, controllable factors (effort, use of specific strategies).

Insisting that attributions are controllable will only be convincing, however, if teachers provide appropriate conditions for students to learn-conditions in which students' efforts really do pay off. There are three conditions that have to be in place for this to happen. First, academic tasks and materials need to be moderated to the right level of difficulty. If you give problems in advanced calculus to a first-grade student, the student will not only fail them but also be justified in attributing the failure to an external factor-task difficulty. If assignments are assessed in ways that produce highly variable, unreliable marks, then students will rightly attribute their performance to an external, unstable source-luck. Both circumstances will interfere with motivation.

Second, teachers also need to be ready to give help to individuals who need it, even if they believe an assignment is easy enough or clear enough that students should not need individual assistance. Readiness to help is always essential because it is often hard to know in advance exactly how difficult a task will prove to be for particular students. Without assistance, a task that proves difficult initially may remain difficult indefinitely, and the student will be tempted to make unproductive attributions about his or her failure ("I will never understand this," "I'm not smart enough," or "It doesn't matter how hard I study," etc.).

Third, teachers need to remember that ability-usually considered a relatively stable factor-often actually changes incrementally over the long term. Recognizing this fact is one of the best ways to bring about actual increases in students' abilities (Blackwell, Trzniewski, \& Dweck, 2007; Schunk, Pintrich, \& Meese, 2008). A middle-years student might play the trumpet in the school band at a high level of ability, but this ability actually reflects a lot of previous effort and a gradual increase in ability. A second grade student who reads fluently may have high current ability to read, but at some point 
in the distant past that same student could not read as well, and even further back they may not have been able to read at all. The increases in ability have happened at least in part because of effort. While these ideas may seem obvious, they can easily be forgotten in the classroom because effort and ability evolve according to very different time frames. Effort and its results appear relatively immediately-a student expends effort this week, this day, or even at this very moment, and the effort (if not the results) are visible right away. But ability may take longer to show itself; a student often develops it only over many weeks, months, or years. 


\subsection{Self-Efficacy}

In addition to being influenced by their goals, interests, and attributions, students' motives are affected by specific beliefs about their personal capacities. In self-efficacy theory the beliefs become a primary, explicit explanation for motivation (Bandura, 1977, 1986, 1997). Self-efficacy is the belief that you are capable of carrying out a specific task or reaching a specific goal. Note that the belief and the action or goal are specific. Self-efficacy is a belief that you can write an acceptable term paper, for example, or repair an automobile, or make friends with the new student in class. These are relatively specific beliefs and tasks. Self-efficacy is not about whether you believe that you are intelligent in general, whether you always like working with mechanical things, or think that you are generally a likeable person. These more general judgments are better regarded as various mixtures of self-concepts (beliefs about general personal identity) or of self-esteem (evaluations of identity). Self-efficacy beliefs, furthermore, are not the same as "true" or documented skill or ability. They are self-constructed, meaning that they are personally developed perceptions. Therefore, discrepancies might exist between a person's self-efficacy beliefs and the person's actual abilities. You can believe that you can write a good term paper, for example, without actually being able to do so, and vice versa: you can believe yourself incapable of writing a paper, but discover that you are in fact able to do so. In this way, self-efficacy is like the everyday idea of confidence, except that it is defined more precisely. And as with confidence, it is possible to have either too much or too little self-efficacy. The optimum level seems to be either at or slightly above true capacity (Bandura, 1997). As explained below, large discrepancies between self-efficacy and ability can create motivational problems for the individual. 


\section{Effects of Self-Efficacy on Students' Behavior}

Self-efficacy may sound like a uniformly desirable quality, but research as well as teachers' experiences suggests that its effects are a bit more complicated than they first appear. Self-efficacy has three main effects, each of which has both a "dark" or undesirable side and a positive or desirable side.

\section{Choice of Tasks}

The first effect is that self-efficacy makes students more willing to choose tasks they already feel confident at succeeding. This effect is almost inevitable, given the definition of the concept of selfefficacy, and has been supported by research on self-efficacy beliefs (Pajares \& Schunk, 2001). For teachers, the effect on choice can be either welcome or not, depending on circumstances. If a student believes that he or she can solve mathematical problems, then the student is more likely to attempt the mathematics homework that the teacher assigns. Unfortunately the converse is also true. If a student believes that he or she is incapable of solving the problem, then the student is less likely to attempt the math homework (perhaps telling themselves, "What's the use of trying?") regardless of their actual ability.

Furthermore, since self-efficacy is self-constructed, it is also possible for students to miscalculate or misperceive their true skills, and these misperceptions themselves can have complex effects on students' motivations. From a teacher's point of view, all is well if students overestimate their capacity and succeed at a relevant task anyway, or if they underestimate their capacity but discover along the way that they can succeed. (The latter instance may even have the result of raising the student's self-efficacy beliefs as a result.) All may not be well, though, if students do not believe that they can 
succeed and therefore do not even try, or if students overestimate their capacity by a wide margin and are then unexpectedly disappointed by a failure that lowers their self-efficacy beliefs.

\section{Persistence at Tasks}

A second effect of high self-efficacy is to increase one's persistence at relevant tasks. If you believe that you can solve crossword puzzles, but encounter one that takes longer than usual, then you are more likely to work longer at the puzzle until you (hopefully) really do solve it. This is probably a desirable behavior in many situations, unless the persistence happens to interfere with other, more important tasks (e.g., what if you should be doing homework instead of working on crossword puzzles?). If you happen to have low self-efficacy for crosswords, on the other hand, then you are more likely to give up early on a difficult puzzle. Giving up early may often be undesirable because it deprives you of a chance to improve your skill by persisting. Then again, the consequent lack of success cause by giving up may provide a useful incentive to improve your crossword skills. And again, misperceptions of capacity make a difference. Overestimating your capacity by a lot (excessively high self-efficacy) might lead you not to prepare for or focus on a task properly, and thereby impair your performance. So as with choosing tasks, the effects of self-efficacy vary from one individual to another and one situation to another. The teacher's task is therefore twofold: first, to discern the variations, and second, to encourage the positive self-efficacy beliefs.

\section{Response to Failure}

High self-efficacy for a task not only increases a person's persistence at the task, but also improves their ability to cope with 
stressful conditions and to recover their motivation following outright failures. Suppose that you have two assignments-an essay and a science lab report-due on the same day, and this circumstance promises to make your life hectic as you approach the deadline. You will cope better with the stress of multiple assignments if you already believe yourself capable of doing both of the tasks than if you believe yourself capable of doing just one of them or (especially) of doing neither. You will also recover better in the unfortunate event that you end up with a poor grade on one or even both of the tasks.

That is the good news. The bad news, at least from a teacher's point of view, is that the same resilience can sometimes also serve nonacademic and non-school purposes. How so? Suppose, instead of two school assignments due on the same day, a student has only one school assignment due, but also holds a part-time evening job as a server at a local restaurant. Suppose, further, that the student has high self-efficacy for both of these tasks; they believe, in other words, that they are capable of completing the assignment as well as continuing to work at the job. The result of such resilient beliefs can easily be a student who devotes a less-than-deal amount of attention to school work, and who even ends up with a lower grade on the assignment than they are capable of of achieving. 


\subsection{Self-Determination Theory}

Common sense suggests that human motivations originate from some sort of inner "need." We all think of ourselves as having various "needs"-a need for food, for example, or a need for companionship-that influences our choices and activities. This same idea also forms part of some theoretical accounts of motivation, though the theories differ in the needs they emphasize or recognize. Some needs may decrease when satisfied (like hunger), but others may not (like curiosity). Either way, needs differ from the self-efficacy beliefs discussed earlier, which are relatively specific and cognitive, and affect particular tasks and behaviors fairly directly.

A recent theory of motivation based on the idea of needs is selfdetermination theory, proposed by the psychologists Edward Deci and Richard Ryan, among others. The theory proposes that understanding motivation requires taking into account three basic human needs:

- Autonomy-the need to feel free of external constraints on behavior

- Competence-the need to feel capable or skilled

- Relatedness-the need to feel connected or involved with others

Note that these needs are all psychological, not physical; hunger and sex, for example, are not on the list. They are also about personal growth or development, not about deficits that a person tries to reduce or eliminate. Unlike food or safety, you can never get enough autonomy, competence, or relatedness. You (and your students) will seek to enhance these continually throughout life. 
The key idea of self-determination theory is that when people (such as you or one of your students) feel that these basic needs are reasonably well met, they tend to perceive their actions and choices to be intrinsically motivated or "self-determined." In that case they can turn their attention to a variety of activities that they find attractive or important, but that do not relate directly to their basic needs. Among your students, for example, some individuals might read books that you have suggested, and others might listen attentively when you explain key concepts from the unit you happen to be teaching.

If one or more basic needs are not met well, however, people will tend to feel coerced by outside pressures or external incentives. They may become preoccupied, in fact, with satisfying whatever need has not been met and thus exclude or avoid activities that might otherwise be interesting, educational, or important.

In proposing the importance of needs, then, self-determination theory is asserting the importance of intrinsic motivation. Intrinsic motivation comes from within the person. You are intrinsically motivated when you find an activity enjoyable, interesting, meaningful, or worthwhile. For example, Cindy looks forward to summer vacation because it gives her plenty of time to read novels. Cindy's prolific reading habits come from her intrinsic motivation to read. In contrast, extrinsic motivation occurs when you expect an external reward, such as a salary or a good grade. Jan does not inherently enjoy reading as much as Cindy does, but she is enrolled in a summer reading program at the local library. Jan receives points each time she completes a book, and she knows that the top five readers at the end of the summer will win prizes. Here, Jan's motivation to read during her summer vacation is primarily extrinsic.

The self-determination version of intrinsic motivation, however, emphasizes a person's perception of freedom, rather than the presence or absence of "real" constraints on action. Self- 
determination means a person feels free, even if the person is also operating within certain external constraints. In principle, a student can experience self-determination even if the student must, for example, live within externally imposed rules of appropriate classroom behavior. To achieve a feeling of self-determination, however, the student's basic needs must be met-needs for autonomy, competence, and relatedness. In motivating students, then, the bottom line is that teachers have an interest in helping students meet their basic needs, and in not letting school rules or the teachers' own leadership styles interfere with or block satisfaction of students' basic needs.

"Pure" self-determination may be the ideal for most teachers and students, of course, but the reality is usually different. For a variety of reasons, teachers in most classrooms cannot be expected to meet all students' basic needs at all times. One reason is the sheer number of students, which makes it impossible to attend to every student perfectly at all times. Another reason is teachers' responsibility for a curriculum, which can require creating expectations for students' activities that sometimes conflict with students' autonomy or makes them feel (temporarily) less than fully competent. Still another reason is students' personal histories, ranging from divorce to poverty, which may create needs in some individuals that are beyond the power of teachers to remedy.

The result from students' points of view is usually only a partial perception of self-determination, and therefore a simultaneous mix of intrinsic and extrinsic motivations. Self-determination theory recognizes this reality by suggesting that the "intrinsic-ness" of motivation is really a matter of degree, extending from highly extrinsic, through various mixtures of intrinsic and extrinsic, to highly intrinsic (Koestner \& Losier, 2004). At the extrinsic end of the scale is learning that is regulated primarily by external rewards and constraints, whereas at the intrinsic end is learning regulated primarily by learners themselves. By assuming that motivation is often a mix of the intrinsic and extrinsic, the job of the teacher 
becomes more realistic. The job is not to expect purely intrinsic motivation from students all the time, but simply to arrange and encourage motivations that are as intrinsic as possible. To do this, the teacher needs to support students' basic needs for autonomy, competence, and relatedness.

To learn more about the levels of intrinsic-extrinsic motivation or other details about self-determination theory, explore the following links:

- http://selfdeterminationtheory.org/

- https://psychology.iresearchnet.com/social-psychology/ control/extrinsic-motivation/

\section{Supporting Autonomy in Learners}

A major part of supporting autonomy is to give students choices wherever possible (Ryan \& Lynch, 2003). The choices that encourage the greatest feelings of self-control are those that concern relatively major issues or that have relatively significant consequences for students, such as whom to choose as partners for a major group project. But choices also encourage some feeling of self-control even when they are about relatively minor issues, such as how to organize your desk or what kind of folder to use for storing your papers at school. It is important, furthermore, to offer choices to all students, including students needing explicit directions in order to work successfully. Avoid reserving choices for only the best students or giving up offering choices altogether to students who fall behind or who need extra help. All students will feel more self-determined and therefore more motivated if they have choices of some sort.

Teachers can also support students' autonomy more directly by minimizing external rewards (like grades) and comparisons among 
students' performance, and by orienting and responding to students' expressed goals and interests. In teaching elementary students about climate change, for example, you can support autonomy by exploring which aspects of this topic have already come to students' attention and aroused their concern. The point of the discussion would not be to find out "who knows the most" about this topic, but to build and enhance students' intrinsic motivations as much as possible. In reality, of course, it may not be possible to succeed at this goal fully-some students may simply have no interest in the topic, for example, or you may be constrained by time or resources from fully individualizing certain activities. But any degree of attention to students' individuality, as well as any degree of choice, will support students' autonomy.

\section{Supporting the Need for Competence}

The most obvious way to make students feel competent is by selecting activities that are challenging but nonetheless achievable with reasonable effort and assistance (Elliott, McGregor, \& Thrash, 2004). Although few teachers would disagree with this idea, there are times when it is hard to put into practice, such as when you first meet a class at the start of a school year and therefore are unfamiliar with the students' backgrounds and interests. But there are some strategies that are generally effective even if you are not yet in a position to know the students well. One is to emphasize activities that require active response from students. Sometimes this simply means selecting projects, experiments, discussions and the like that require students to do more than simply listen. Other times it means expecting active responses in all interactions with students, such as by asking questions that call for "divergent" (multiple or elaborated) answers. In a social studies class, for example, try asking "What are some ways we could find out more about our community?" instead of "Tell me the three best ways to find out about our community." 
The first question invites more divergent, elaborate answers than the second.

Another generally effective way to support competence is to respond and give feedback as immediately as possible. Tests and term papers help subsequent learning more if returned-with comments-sooner rather than later. Discussions teach more if you include your own ideas in them, while still encouraging students' input. Small group and independent activities are more effective if you provide a convenient way for students to consult authoritative sources for guidance when needed, whether the source is you personally, a teaching assistant, a specially selected reading, or even a computer program. In addition, you can sometimes devise tasks that create a feeling of competence because they have a "natural" solution or ending point. Assembling a jigsaw puzzle of the community, for example, has this quality, and so does creating a jigsaw puzzle of the community if the students need a greater challenge.

\section{Supporting the Need to Relate to Others}

The main way of support students' need to relate to others is to arrange activities in which students work together in ways that are mutually supportive, that recognize students' diversity, and minimize competition among individuals. Having students work together can happen in many ways. You can, for example, deliberately arrange projects that require a variety of talents; some educators call such activities "rich group work" (Cohen, 1994). While studying medieval society after begin place in small groups, for example, one student can contribute drawing skills, another can contribute writing skills, and still another can contribute dramatic skills. The result can be a multi-faceted presentation-written, visual, and oral. The groups needed for rich group work provide for 
students' relationships with each other, whether they contain six individuals or only two.

As a teacher, you can add to these organizational strategies by encouraging the development of your own relationships with class members. Your goal, as teacher, is to demonstrate caring and interest in your students not just as students, but as people. The goal also involves behaving as if good relationships between and among class members are not only possible, but ready to develop and perhaps even already developing. A simple tactic, for example, is to speak of "we" and "us" as much as possible, rather than speaking of "you students." Another tactic is to present cooperative activities and assignments without apology, as if they are in the best interests not just of students, but of "all of us" in the classroom, yourself included.

\section{Keeping Self-Determination in Perspective}

In certain ways self-determination theory provides a sensible way to think about students' intrinsic motivation and therefore to think about how to get them to manage their own learning. A particular strength of the theory is that it recognizes degrees of selfdetermination and bases many ideas on this reality. Most people recognize combinations of intrinsic and extrinsic motivation guiding particular activities in their own lives. We might enjoy teaching, for example, but also do this job partly to receive a paycheck. To its credit, self-determination theory also relies on a list of basic human needs-autonomy, competence, and relatedness-that relate comfortably with som of the larger purposes of education.

Although these are positive features for understanding and influencing students' classroom motivations, some educators and psychologists nonetheless have lingering questions about the 
limitations of self-determination theory. One is whether merely providing choices actually improves students' learning, or simply improves students' satisfaction with learning. There is evidence supporting both possibilities (Flowerday \& Schraw, 2003; Deci \& Ryan, 2003), and it is likely that there are teachers whose classroom experience supports both possibilities as well. Another question is whether it is possible to pay too much attention to students' needs-and again there is evidence that both favors and contradicts this possibility. Too many choices can actually make anyone (not just a student) frustrated and dissatisfied with the choice the person actually does make (Schwartz, 2004). Furthermore, differentiating activities to students' competence levels may be impractical if students are functioning at extremely diverse levels within a single class, as sometimes happens. Differentiating may be inappropriate, too, if it holds a teacher back from covering key curriculum objectives that students need and at least some students are able to learn. These are serious concerns, though not serious enough to give up offering choices to students or to stop differentiating instruction altogether. 


\subsection{Expectancy-Value Theory}

Motivation is affected by several factors, including reinforcement for behavior, but especially also students' goals, interests, and sense of self-efficacy and self-determination. The factors combine to create two general sources of motivation: students' expectation of success and the value that students place on a goal. Viewing motivation in this way is often called the expectancy-value model of motivation (Wigfield \& Eccles, 2002; Wigfield, Tonk, \& Eccles, 2004), and sometimes written with a multiplicative formula as follows:

\section{expectancy $*$ value $=$ motivation}

The relationship between expectation and value is "multiplicative" rather than additive because in order to be motivated, it is necessary for a person to have at least a modest expectation of success and to assign a task at least some positive value. If you have high expectations of success but do not value a task at all (mentally assign it a "0" value), then you will not feel motivated at all. Likewise, if you value a task highly but have no expectation of success about completing it (assign it a "0" expectancy), then you also will not feel motivated to perform. Expectancies are the result of various factors, but particularly the goals held by a student, and the student's selfefficacy, as discussed earlier in this chapter. A student with mastery goals and strong self-efficacy for a task, for example, is likely to hold high expectations for success. Values are also the result of various factors, but especially students' interests and feelings of self-determination. A student who has a lasting personal interest in a task or topic and is allowed to choose it freely is especially likely to value the task, and therefore to feel motivated.

Ideally, both expectancies and values will be high when students are confronted with learning critically important tasks. The reality, however, is that students sometimes do not expect success, nor do they necessarily value success when it is attainable. How can 
a teacher respond to low expectations and low valuing? In brief, raising low expectations depends on adjusting task difficulty so that success becomes a reasonable prospect; a teacher must make tasks neither too hard nor too easy. Reaching this general goal depends in turn on thoughtful, appropriate planning, i.e., selecting reasonable objectives, adjusting them on the basis of experience, finding supportive materials, and providing students with help when needed.

Raising the value of academic tasks is equally important, but the general strategies for doing so are different than for raising expectations. Increasing value requires linking the task to students' personal interests and prior knowledge, showing the utility of the task to students' future goals, and showing that the task is valuable to other people the students respect. 


\subsection{Designing for Motivation}

How do educational technologist include motivation in the design of educational experiences and products? In addition to the ideas presented above, John Keller's ARCS model is useful for providing guidelines. This model was developed by synthesizing many of the motivational theories highlighted above. The acronym ARCS stands for:

- Attention-start by gaining the learner's attention by arousing curiosity or presenting a problem to be solved.

- Relevance-demonstrate to the learner that the lesson will be useful to them or consistent with their goals.

- Confidence-create an expectation of success.

- Satisfaction-enhance the learners' feelings of satisfaction by providing appropriate rewards for achievement.

To achieve these four goals, Keller (Keller \& Suzuki, 20014) outlines a ten-step design process, which is discussed in the chapter focusing on instructional design. You can find out much more about the ARCS model here: https://www.arcsmodel.com/. 


\subsection{Chapter Summary}

This chapter introduced several theories of motivation. While they all emphasize different aspects of motivation, they are not mutually exclusive, and in fact they overlap. While many of the examples in this chapter involved children, the general concepts apply to adult learners as well. The next chapter will focus explicitly on the needs and motivations of adult learners. 


\subsection{Chapter 4 References}

Bandura, A. (1977). Self-efficacy: Toward a unifying theory of behavioral change. Psychological Review, 84, 191-215.

Bandura, A. (1986). Social foundations of thought and action: A social cognitive theory. Englewood Cliffs, NJ: Prentice Hall.

Bandura, A. (1997). Self-efficacy: The exercise of control. New York: Freeman.

Blackwell, L., Trzniewski, K., \& Dweck, C. (2007). Implicit theories predict achievement across an adolescent transition: a longitudinal study. Child Development, 78, 246-263.

Brophy, J. (2004). Motivating Students to Learn (Second ed.). Mahwah, N.J.: Lawrence Erlbaum Associates.

Burke, M. \& Sass, T. (2006). Classroom peer effects and student achievement. Paper presented at the annual meeting of the American Economic Association, Boston, USA.

Cohen, E. (1994). Designing groupwork: Strategies for the heterogeneous classroom, 2nd edition. New York: Teachers' College Press.

Dowson, M. \& McInerney, D. (2003). What do students say about their motivational goals? Toward a more complex and dynamic perspective on student motivation. Contemporary Educational Psychology, 28, 91-113.

Dweck, C. (2000). Self-theories: Their role in motivation, personality, and development. Philadelphia: Psychology Press.

Dweck, C. (2006). Mindset: The new psychology of success. New York: Random House. 
Elliott, A., McGregor, H., \& Thrash, T. (2004). The need for competence. In E. Deci \& R. Ryan (Eds.), Handbook of selfdetermination research (pp. 361-388). Rochester, NY: University of Rochester Press.

Flowerday, T., Shraw, G., \& Stevens, J. (2004). Role of choice and interest in reader engagement. Journal of Educational Research, 97, 93-103.

Harzckiewicz, J., Barron, K., Tauer, J., \& Elliot, A. (2002). Short-term and long-term consequences of achievement goals. Journal of Educational Psychology, 92, 316-320.

Keller, J. M., \& Suzuki, K. (2004). Learner motivation and e-learning design: a multinationally validated process. Journal of Educational Media, 29. doi:10.1080/1358t65042000283084

Koestner, R. \& Losier, G. (2004). Distinguishing three ways of being highly motivated: a closer look at introjection, identification, and intrinsic motivation. In E. Deci \& R. Ryan (Eds.), Handbook of selfdetermination research (pp. 101-122). Rochester, NY: University of Rochester Press.

Midgley, C., Kaplan, A., \& Middleton, M. (2001). Performanceapproach goals: Good for what, for whom, and under what conditions, and at what cost? Journal of Educational Psychology, $93,77-86$.

Pajares, F. \& Schunk, D. (2001). Self-beliefs and school success: Selfefficacy, self-concept, and school achievement. In . Riding \& S. Rayner (Eds.), Perception (pp. 239-266). London: Ablex Publishing.

Ryan, R. \& Lynch, M. (2003). Philosophies of motivation and classroom management. In R. Curren (Ed.), Blackwell companion to philosophy: A companion to the philosophy of education (pp. 260-271). New York, NY: Blackwell.

Schunk, D., Pintrich, P., Meese, J. (2008). Motivation in education: 
Theory, research and applications. New York: Pearson Professional.

Schwartz, B. (2004). The paradox of choice: Why more is less. New York: Ecco/Harper Collins.

Urdan, T. (2004). Predictors of self-handicapping and achievement: Examining achievement goals, classroom goal structures, and culture. Journal of Educational Psychology, 96, 251-254.

Weiner, B. (2005). Motivation from an attribution perspective and the social psychology of perceived competence. In A. Elliot \& C. Dweck (Eds.), Handbook of Competence and Motivation, pp. 73-84. New York: Guilford Press.

Wigfield, A. \& Eccles, J. (2002). The development of achievement motivation. San Diego, CA: Academic Press.

Wigfield, A., Tonk, S., \& Eccles, J. (2004). Expectancy-value theory in cross-cultural perspective. In D. McInerney \& S. van Etten (Eds.), Research on Sociocultural Influences on Motivation and Learning. Greenwich, CT: Information Age Publishers.

Wolters, C. (2004). Advancing achievement goal theory: Using goal structures and goal orientations to predict students' motivation, cognition, and achievement. Journal of Educational Psychology, 96, 236-250.

The majority of the text in this chapter is taken from Chapter 6 of the open access text Educational Psychology, 3rd Edition, 2011 by Kelvin Seiffert and Rosemary Sutton. (Minor modifications to words and phrases were made as needed and transitional text added to fit the current context.) 


\section{CHAPTER 5: ADULT \& WORKPLACE LEARNING}

While the basic principles of learning (e.g., memory, attention, socio-cultural influences, etc.) may apply broadly to learners of all ages, both the learner's level of development and the learning context change with age. For example, adult learners have more prior knowledge and life experience than children do, they generally have literacy skills, and they may have more competing demands on their time. Therefore, researchers have looked specifically at adult learning or learning in the workplace. Three theories of adult or workplace learning are briefly summarized here: Andragogy, Community of Practice, and Transformative Learning. 



\section{I Andragogy}

The best-known theory of adult learning is Malcolm Knowles' theory of Andragogy. The term means "leading a man" and sets up a contrast with pedagogy, which means "leading a child." The theory is based on the following six assumptions (as described in Merriam et al., 2007):

1. People become less dependent and more self-directed as they mature

2. Adults have a rich set of life experiences that affect how they learn

3. Adult readiness to learn is related to the roles adults play in their lives and the contexts in which they live and work

4. Adults need immediate application for their learning, and are more interested in learning to solve problems rather than to acquire knowledge about academic subjects

5. Adult motivation comes from internal rather than external sources

6. Adults need to understand the relevance of what they are learning

Like all theories, andragogy has its critics. Some argue that it is a model for teaching or instructional design but does not have the explanatory power of a learning theory. Others argue that the assumptions underlying andragogy are not unique to adults. For example, children also benefit from relevance and intrinsic motivation.

For more information about andragogy, see the following links:

- http://teachinglearningresources.pbworks.com/w/page/ 30310516/Andragogy-Adult\%20Learning\%20Theory. 
An interactive or media element has been excluded from

믓 this version of the text. You can view it online here:

https://open.library.okstate.edu/

foundationsofeducationaltechnology/?p=152

- https://youtu.be/vLoPiHUZbEw ( 8-minute video) 


\subsection{Community of Practice}

Community of practice is a concept developed by Jean Lave and Etienne Wenger, and arose out of their study of workplace learning, though the concept can also apply in schools or informal settings. The basic concept of community of practice is that groups of people engaged in a common practice (e.g., job, hobby, etc.) have both explicit and tacit knowledge, which is passed from "old-timers" to "newcomers" through social processes. Not every community is a community of practice. Wenger (1998) describes the essential features of a community of practice as follows:

- A domain, or shared area of distinct competence or expertise. This can be a formal profession or something less formal, such as a hobby, but it is more goal-oriented than just a gathering of friends.

- A community where members work together, share information, and help each other.

- A practice with a repertoire of tools, methods, etc.

Newcomers join a community of practice by first engaging in legitimate peripheral participation, where they contribute to the practice despite their novice skill level. Their participation is peripheral because it is "an approximation of full participation that gives exposure to actual practice" (Wenger, 1998, p.10), but also legitimate if they are accepted as a member by the community. As they gain skills and knowledge, the newcomers gradually progress to full participation and the mentoring of other newcomers.

For more information about communities of practice, see: https://scholarsbank.uoregon.edu/xmlui/bitstream/handle/1794/ $11736 /$

A\%20brief\%20introduction\%20to\%20CoP.pdf?sequence\%E2\%80\% B0=\%E2\%80\%B01 


\section{$5 \cdot 3$ Transformative Learning}

While there are several theories that focus on transformation, the best known if the theory developed by Jack Mezirow. The term transformative refers to the idea that adults can reflect on and make sense of their experiences in a way that changes them is some way. This process occurs when learners change either their frame of reference by altering either their habits of mind (assumptions through which experience is filtered) or their point of view (beliefs and attitudes).

The transformative learning process involves:

\section{Experience}

2. Critical reflection on the experience

3. Reflective discourse (seeking out and discussing a variety of opinions and perspectives related to the experience)

4. Action (a decision, plan, or specific action prompted by the process)

For more detail on transformative learning, see the following resources:

- http://onlinelibrary.wiley.com/doi/10.1002/ace.7401/epdf

- https://www.iup.edu/WorkArea/ DownloadAsset.aspx?id=18335 


\subsection{Chapter Summary}

While many aspects of human cognition, and thus of teaching and learning, are similar for children and adults, there are many theories and models that focus on what makes adult learning unique. Andragogy emphasizes the life experience and self-directed behavior of adults, community of practice explores how learning occurs informally through goal-directed social interaction, and transformative learning emphasizes adults' potential for transformation through deep reflection. These theories improve the ability of educational technologists and instructional designers to create appropriate learning experiences for learners of all ages. 


\subsection{Chapter 5 References}

Merriam, S. B., Caffarella, R., \& Baumgartner, L. M. (2007). Learning in adulthood: A comprehensive guide. San Francisco: John Wiley \& Sons, Inc.

Wenger, E. (1998). Communities of practice: Learning, meaning, and identity. Cambridge: Cambridge University Press. 


\section{CHAPTER 6: COMMUNICATION}

Because teaching and learning involve an act of communication, educators looked to communication theory to inform the teaching and learning process. Early models of communication and message design focused on the transmission of information from sender (or teacher) to receiver (or student) (Bishop, 2014). 



\section{I Communication Models}

The Shannon-Weaver model is one foundational theory of information transmission. It features a sender who encodes a message to send over a communication channel. A receiver at the other end then decodes the message. Watch the following sixminute video for an overview of the model:

\footnotetext{
An interactive or media element has been excluded from this version of the text. You can view it online here:

https://open.library.okstate.edu/

foundationsofeducationaltechnology/?p=162
}

https://youtu.be/etcIX0aC-4E (6:18 minutes)

Another model, by Wilber Schramm, built upon these same concepts, but also acknowledged the interaction between sender and receiver by considering what he called "fields of experience," or whether the sender and receiver had enough shared experience to be able to communicate effectively. The following eight-minute video discusses Schramm's model and applies it explicitly to teaching and learning:

An interactive or media element has been excluded from this version of the text. You can view it online here: 
https://open.library.okstate.edu/

foundationsofeducationaltechnology/?p=162

https://youtu.be/KZKacQqd8LE (7:39 minutes)

While all teachers are concerned with crafting their instructional messages in a way that students, can receive and understand, educational technologist have the added concern of making sure the technology facilitates communication rather than impedes it. When technology mediates communication between teacher and student, there is a risk that it will introduce noise into the communication process. At the same time, technology can provide opportunities to encode a message in meaningful ways. 


\subsection{Instructional Message Design}

The concept of instructional message design arose from the intersection of these communication theories and learning theories, which shifted the focus from the actions of the sender to how the message is understood by the receiver (Bishop, 2014). According to Bishop (2014), feedback (reinforcement or punishment) was viewed as an important part of the instructional message in the behaviorist era, while under the cognitive perspective the emphasis shifted to facilitating information processing by the learner.

Watch the following TEDx talk about how to design effective PowerPoint slides. While designers and researchers may argue over some of the details of this presentation (e.g., the speaker's prescription to use dark slide backgrounds is quite controversial and definitely not applicable in all situations!), it provides an excellent example of how cognitive principles and design principles are combined to create guidelines for instructional message design:

\footnotetext{
An interactive or media element has been excluded from

鱼 this version of the text. You can view it online here:

https://open.library.okstate.edu/

foundationsofeducationaltechnology/?p=164
}

https://youtu.be/Iwpi1Lm6dFo (20:31 minutes).

Bishop (2014) suggests that in light of the evolution of learning theory toward more constructivist paradigms (see chapter 3 of this 
book), instructional message design needs to be viewed more broadly than it has in the past. She suggests Brent Wilson's Four Pillars of Practice as a starting point for this broader view. Wilson's four pillars (as summarized in Bishop, 2014) are as follows:

1. Individual cognition and behavior-understanding how learners think and learn

2. Social and cultural learning-how the social and cultural context affects learning

3. How values are communicated in design

4. The aesthetic experience of learning 


\subsection{Chapter Summary}

While theories of communication and theories of learning have evolved over the years, and the nature of the connection between them has shifted, it is useful for us as educators to keep in mind that instruction, whether in a face-to-face classroom, an online classroom, or even a self-service e-learning application, is an act of communication. An understanding of the communication process therefore underlies all we do as educators. 


\subsection{Chapter 6 References}

Bishop, M. J. (2014). Instructional message design: Past, present, and future relevance. In Handbook of research on educational communications and technology (pp. 373-383). Springer New York. 


\section{CHAPTER 7: RESEARCH IN EDUCATIONAL TECHNOLOGY}

What does it mean to "know" something, and how much are we really capable of knowing?

These may seem like simple questions, but as you will see, there are different philosophies that approach them from different angles and arrive at different conclusions. This chapter provides a very brief introduction to the major research traditions and the types of questions and methods that are generally associated with those traditions. While there are many views on the topic, some overlapping and some conflicting, this chapter focuses mainly on the work of Cresswell (2003). It is not, therefore, an exhaustive summary of all possible approaches to research, but rather a starting place for understanding the differences between some of the historical traditions. 



\section{I Views of Knowledge}

Research traditions stem from people's beliefs about truth and knowledge. Creswell (2003) identifies four research traditions that evolve from different knowledge claims: postpositivism, constructivism, advocacy, and pragmatism.

\section{Postpositivism}

Postpositivism evolved from the older positivist view, which held strong beliefs about reality and truth being "out there in the world" waiting to be discovered through rigorous, objective testing. At the time when scientific research methods were emerging and people were learning more and more about the physical world, there was a great deal of confidence that the truth could be fully known and understood by careful, controlled observation. These positivist beliefs moderated over time, especially with respect to the social sciences, and led to an acknowledgment that human behavior does not follow laws equivalent to the laws of physics. (In fact, even our understanding of reality in the physical world has changed over the years.) Postpositivism, then, follows from the positivist tradition but in a moderated and, perhaps, more humble form. It retains the belief that there is objective truth in the world, and that if we make an effort to protect our research projects from our personal biases we can uncover a tentative approximation of truth, recognizing that our understanding will always be incomplete and imperfect.

\section{Constructivism}

Constructivism holds that reality, at least as it applies to the social 
sciences, is constructed by humans. That is, constructivists do not believe in an objective truth waiting to be discovered. Rather, meaning is constructed in human minds and through human interaction. This relatively more subjective view leads to very different beliefs about what we can know and understand. To understand the world, in the constructivist view, we need to seek understanding of human experience.

\section{Advocacy}

The advocacy (sometimes called critical) tradition is much more purposeful in its goals for research. While beliefs about reality and knowledge are probably similar to the constructivist tradition, those questions are not the focus of attention. The primary concern in this tradition is the power structures in society, which can oppress some groups of people. In the advocacy tradition the purpose of research is to find a way to facilitate change. The desired end goal is to emancipate people who are oppressed by a power structure, and to support them in implementing a desired change.

\section{Pragmatism}

The pragmatic perspective focuses on practicality and expediency. Questions about truth and reality are almost "off the radar screen" in this tradition as researchers focus on the most effective way to answer a specific question in a given situation. 


\subsection{Research Traditions}

The different beliefs about reality and knowledge described above lead to different research questions and different ways of conducting research. Quality research demonstrates consistency between the research tradition, research questions, type of data collected, methods of data analysis, conclusion drawn, and claims about how widely the conclusions can be generalized (applied to other situations beyond the research study).

\section{Postpositivist Research}

In the postpositivist tradition, the job of researchers is to uncover to the best of their ability (or at least approximate) objective truth. They use established theory to generate research questions that can be answered through objective observation and/or experimentation. They form a theory-based hypothesis and then test it by collecting and analyzing data, which is most often quantitative. They look for evidence that either supports or does not support the hypothesis, recognizing that conclusions from any one study will always be tentative and not certain. You will often see phrases like "How does X affect Y?" or "Does X cause Y?" in their written reports. Postpositivist researchers make every effort to control for extraneous factors and take careful measurements. The ultimate goal is to make a discovery that has some measure of generalizability, or applicability to other similar contexts.

Experimental design is common under this tradition. For example, if researchers want to know if a gamified math lesson helps students learn basic algebra, they might randomly assign a group of similar students to learn an algebra lesson either with the game or in a traditional classroom. Random assignment minimizes the risk that 
pre-existing differences between the two groups will "contaminate" the result. If random assignment is not possible, they might instead do a quasi-experiment where they use two existing groups with similar characteristics, such as two classrooms in the same school. Experimenters then give both groups a test on the material before the intervention to verify both groups have similar (lack of) knowledge of the lesson. After each group completes the intervention they are tested again to see if the groups achieved different average scores.

If the group completing the traditional lesson has an average score of $8 / 10$ on the test and the group completing the gamified lesson averages $9 / 10$, does that demonstrate that the gamified version was better? Not necessarily. The significance of the difference must be verified statistically before researchers can claim they have evidence supporting the usefulness of the gamified lesson.

Experiments and quasi-experiments are not the only types of studies done under a postpositivist perspective. Descriptive studies (often, but not always, accomplished with surveys) and correlational studies (explorations of whether two variables appear to change in relation to each other) are also common.

All of the research traditions come with their own set of strengths and limitations, which should be readily acknowledged by researchers. The strength of postpositivist research is its ability to produce generalizable results that can be applied in other settings with characteristics similar to the research setting. A limitation is that its focus on patterns and trends neglects the experiences of individuals. Postpositivist research is good at addressing questions of "What works?" or "Which is better?" (e.g., "Does a gamified algebra lesson improve test scores?") but does not usually address questions like "What does the process look like?" or "What are the students' perceptions of their experience?" 


\subsection{Constructivist Research}

Constructivist researchers seek to understand the experience of research participants in order to discover the participants' subjective truth or perceptions. In contrast to postpositivist researchers who begin with a theory and a hypothesis, constructivists more often start with a broad question, and allow participants to drive the direction of the data collection. Constructivists do value established theory, but they are more likely to use it to support the interpretation of the data they have collected, rather than using it to support hypotheses or questions at the beginning of a study.

Constructivist researchers don't claim objectivity, but instead acknowledge and describe their subjectivity as they co-construct understanding with their participants. For example, a white, female researcher interviewing a group of Latina adolescent girls might discuss ways in which she is and is not equipped to understand the perspective of these participants. Because the researcher was herself once an adolescent girl, she may have some shared experience with the study participants. At the same time there are differences (due to ethnicity, reaching adolescence in a different time period, etc.) that could introduce misunderstandings as the researcher seeks to interpret the participants' words and gestures. In addition, because the researcher is older and in a position of authority, her presence might influence what the participants choose to disclose. Constructivist researchers do their best to anticipate these issues and acknowledge them as part of their reporting.

Constructivist researchers often (though not always) use qualitative data collection and analysis. They are less likely (compared to postpositivists) to use tests and surveys that can be analyzed with statistics. Instead, they gather qualitative data, such as from 
interviews, focus groups, and observations, that allow the participants to describe or demonstrate their experiences. For example, the researcher described above might interview the adolescent girls to find out how they experienced the gamified math lesson. Did they find the competitive element of the lesson motivating, threatening, or something else the researcher hadn't thought of? How is the gamified lesson reflected in their feelings about their ability to learn algebra? Reports of research findings may feature quotations of the participants' words, detailed descriptions of their interactions, or similar rich descriptive information. Data analysis often involves looking for themes that emerge from this rich data, which are sometimes organized into categories. There are a variety of approaches to qualitative research, and a detailed description of them is outside the scope of this chapter. However, as you read journal articles, you will see discussion of methodologies like ethnography, phenomenology, qualitative case studies, and several others.

Because constructivist researchers believe that knowledge emerges within a specific context, they do not claim their research findings are widely generalizable. In the example above, the researcher interviewed a particular group of Latina adolescent girls in a particular school, and the experiences of these girls might not reflect the experience of other Latina adolescent girls in that school, let alone in a different school or city. While this lack of generalizability is acknowledged as a limitation, it is not viewed as a deficiency. When truth and knowledge are viewed as human constructions created in specific contexts, generalizability is not deemed appropriate or desirable.

The strength of the constructivist research tradition is its focus on the experiences of individual participants and on processes and experiences over time. A limitation is that it does not allow for conclusions that can be generalized to other populations. For example, a research project consistent with the constructivist perspective would not tell us the best way to implement a gamified 
algebra lesson to improve learning or math confidence in adolescent girls.

\section{Advocacy Research}

In the advocacy tradition the researcher is seen as a facilitator, with the participants as equal partners. The focus of the research is not the acquisition of knowledge for its own sake, but rather on empowering the participants and their communities. The researcher seeks to support participants as they discover ways to emancipate themselves from an unjust power structure. The end result is usually a concrete plan for action. Action research is one methodology associated with the advocacy tradition. Research questions frequently center on issues related to race, class, gender, and the effects of the prevailing power structure on marginalized groups of people. Advocacy research is often guided by critical theory (see https://en.wikipedia.org/wiki/Critical theory); it goes beyond mere interpretation or understanding, and aims to critique what its proponents see as the different ways in which dominant ideologies manifest in various contexts.

\section{Pragmatism in Research}

In the pragmatic research tradition, researchers do not take a firm position on whether reality and knowledge are objective or subjective. Consequently, their work can reflect elements of postpositivist and constructivist traditions, and their methodologies mix both quantitative and qualitative elements. In some studies, the balance of quantitative and qualitative is fairly equal. For example, a researcher may collect both rich descriptive data and test scores from the adolescent girls doing the gamified algebra lesson in an 
effort to understand how the gamified pedagogy and the girls' perceptions worked together to shape their learning experience. In other cases one element may be subordinate to the other. For example, the researcher may be primarily interested in finding out how the gamified algebra lesson affects test scores, but may also want to interview selected participants to enhance understanding of the result.

A strength of this research tradition is the flexibility it provides to approach a single research topic in multiple ways. A limitation is its lack of clear commitment to a philosophical viewpoint. Some argue that it is not really possible to be so flexible in one's view of reality and truth, and that pragmatism is often a disguised form of postpositivsim (Denzin, 2010). 


\subsection{Chapter Summary}

This chapter briefly introduced the four primary research traditions: postpositivism, constructivism, advocacy, and pragmatism. A good quality research project will be situated in one of these traditions and will carry its beliefs and perspectives consistently throughout the study. When you read a journal article that reports on a research project, keep this need for consistency in mind. Do the researchers seem to believe that truth is objective and knowable (though maybe not perfectly), or do they believe truth is more subjective and knowledge is context-dependent? Then look at the research questions to see if they correspond with that perspective. For example, researchers who believe truth is objective and discoverable should ask research questions that emphasize things that can be measured quantitatively. Next, evaluate how well their research methods match the questions they asked. For example, postpositivists seeking to answer cause-and-effect questions will use experimental design, while constructivists seeking to explore perspectives and experience will use a method, such as interviews, that provides rich data reflecting the participants' perspectives. Finally, the conclusions that they draw at the end should be consistent with what came before. They should not, for example, make cause-and-effect claims if their data came from qualitative interviews.

For more background and detail on different research traditions, you are encouraged to watch the video linked below. While it is addressed to nursing students, it is relevant to all researchers and consumers of research reports, as it provides an excellent overview of the "big ideas" from this chapter: 
An interactive or media element has been excluded from

믓 this version of the text. You can view it online here:

https://open.library.okstate.edu/

foundationsofeducationaltechnology/?p=358

https://youtu.be/hCOsY5rkRs8 (11:59 minutes). 


\subsection{Chapter 7 References}

Creswell, J. W. (2003). Research design: Qualitative, quantitative, and mixed methods approaches (2nd ed.). Thousand Oaks, CA: Sage.

Denzin, N. K. (2010). Moments, mixed methods, and paradigm dialogs. Qualitative inquiry, 16(6), 419-427. 



\section{CHAPTER 8: INSTRUCTIONAL DESIGN}

Design can be defined as "a systematic process, represented by models, based on theory, and grounded in data while focused on problem solving" (Tracey \& Baaki, 2014, p. 2). Instructional designers apply this systematic design process to creating experiences that facilitate learning. 



\section{I Instructional Design Models}

There are several models that can be used to scaffold a systematic approach to the design and development of instructional materials and learning experiences. Each model has its unique features, but there is also a great deal of overlap. The 5-minute video linked below provides an overview of several models. The remainder of the chapter highlights a few important models in more detail.

\footnotetext{
므 An interactive or media element has been excluded from this version of the text. You can view it online here:

https://open.library.okstate.edu/

foundationsofeducationaltechnology/?p=180
}

https://youtu.be/dWqc3s64LIU

\section{The ADDIE Framework}

ADDIE is an acronym that stands for Analysis, Design, Development, Implementation, and Evaluation. This framework outlines a systematic approach to designing learning experiences. It is often used as-is to outline the instructional design process, but its principles also underlie the more specific instructional design models highlighted below.

For an overview of the ADDIE process, watch the following five videos: 
An interactive or media element has been excluded from this version of the text. You can view it online here:

https://open.library.okstate.edu/

foundationsofeducationaltechnology/?p=180

- Analysis: https://youtu.be/

JZdv5lrJs4U?list=PL20E84CD77B301A20

(5:26 minutes)
An interactive or media element has been excluded from
즈 this version of the text. You can view it online here:

https://open.library.okstate.edu/

foundationsofeducationaltechnology/?p=180

- Design: https://youtu.be/

BhLIiF9QyTo?list=PL20E84CD77B301A20

(6:40 minutes)

An interactive or media element has been excluded from

믓 this version of the text. You can view it online here:

https://open.library.okstate.edu/

foundationsofeducationaltechnology/?p=180 
- Development: https://youtu.be/

VzYDNWhQWYA?list=PL20E84CD77B301A20 (3:19 minutes)

An interactive or media element has been excluded from

믓 this version of the text. You can view it online here:

https://open.library.okstate.edu/

foundationsofeducationaltechnology/?p=180

- Implementation: https://youtu.be/

CBoI0wBo4vw?list=PL20E84CD77B301A20

(7:12 minutes)

An interactive or media element has been excluded from

는 this version of the text. You can view it online here:

https://open.library.okstate.edu/

foundationsofeducationaltechnology/?p=180

- Evaluation: https://youtu.be/

q8yky6-P1Uw?list=PL20E84CD77B301A20

(3:39 minutes)

\section{Dick \& Carey}

One of the best known, foundational theories of instructional design 
is the model developed by Walter Dick and Lou Carey developed a comprehensive instructional design model in the late 1970s. See the following five-minute video for an overview of the Dick and Carey model:

An interactive or media element has been excluded from

믓 this version of the text. You can view it online here:

https://open.library.okstate.edu/

foundationsofeducationaltechnology/?p=180

https://youtu.be/-sq2vn8Tm-U

You can also read more about this model at

https://elearningindustry.com/9-steps-to-apply-the-dick-andcarey-model-in-elearning

\section{Participatory Design Processes}

We have already discussed the importance of understanding your target learners when designing and educational experience. Learner analysis is, for example, an important component of the analysis phase of the ADDIE framework. This approach still maintains a certain separation between designer and end user or learner; the designer provides something and the learner receives the product the designer created.

Participatory design is a model that breaks down the designeruser separation and brings the end user into the process from the 
ground up. The following $\sim 18$ minute video provides an excellent introduction to participatory design:

An interactive or media element has been excluded from

믓 this version of the text. You can view it online here:

https://open.library.okstate.edu/

foundationsofeducationaltechnology/?p=180

https://youtu.be/U3Hn-sONiRg

(Note that this video makes reference to a different design model - the double diamond - than the ones we have reviewed here. As instructional designers we would plug in an ID model or framework, such as ADDIE, in place of the double diamond.) 


\subsection{Cultural Competence in Instructional Design}

In our increasingly globalized economy and increasingly multicultural local contexts, consideration of culture is gaining attention among instructional designers and educational technology researchers. Dr. Patricia A. Young from the University of Maryland is one of the leading researchers in this area of cultural competence in instructional design. Her work is based on a definition of culture as "the patterns of behavior and thinking by which members of groups recognize and interact with one another" (Scheel \& Branch, 1993 as cited in Young, 2008b, p. 8). She identifies two trends in the development of communications technology internationalization and localization - that have made consideration of culture salient. Internationalization "seeks to eliminate culture, thus making the product one that can be used by all or a universal design" while localization "tailors products to the needs of a target audience" (Young, 2008b, p. 7). Designers attempting to design for an international market may, for example, avoid humor, metaphor, and colloquial language in order to create a product that they believe will translate into any language and cultural context. Designers wishing to localize, on the other hand, would study the local context and target the product to fit that context.

Young (2008b) advocates a culture based model (CBM), "an intercultural, instructional design framework that guides designers through the management, design, development, and assessment process while taking into account explicit culture-based considerations (p. 107). The acronym ID-TABLET represents the eight major areas of concern when incorporating culture into instructional design. These areas are: 
- Inquiry - a series of questions for designers can use to constantly verify the product they are creating is appropriate for the audience

- Development - design factors to keep in mind as decisions are made and problems solved during the development process

- Team - decision making is a team effort including all needed areas of expertise, including a cultural expert

- Assessments - assessments at all levels of the process, including ongoing critical evaluation of the assessment process itself and culture-specific assessments.

- Brainstorming - guidelines for gathering input from multiple stakeholders during the design process

- Learners - "support the learner's cultural frame of reference while meeting the learning outcomes of the project" (p. 114)

- Elements - elements of culture, as defined in a variety of disciplines such as anthropology and psychology

- Training - providing product-specific and culture-based training to instructors

While the details of how this model is used is outside the scope of this chapter, the most important point to note is that it is not a mere "layering" of culture onto an existing ID model, but rather a new model that seeks to embed cultural awareness in each step. 


\subsection{Careers in Instructional Design}

Instructional designers are employed in a variety of different environments, including manufacturing, finance, healthcare, and the military, and higher education, though the specific job titles may vary by industry. In PK-12 school environments the title of "instructional designer" is less common, but curriculum developers, technology coaches, and others may perform instructional designrelated work.

Here are two helpful videos (which have some overlapping content but with slightly different emphasis) that summarize what instructional designers do:

\footnotetext{
An interactive or media element has been excluded from

믓 this version of the text. You can view it online here:

https://open.library.okstate.edu/

foundationsofeducationaltechnology/?p=184
}

- https://youtu.be/f2q-SYS2Kbc 
An interactive or media element has been excluded from

믓 this version of the text. You can view it online here:

https://open.library.okstate.edu/

foundationsofeducationaltechnology/?p=184

- https://youtu.be/w0iQgStGND4 


\subsection{Chapter Summary}

This chapter introduced the ADDIE framework and a sample of instructional design models. It also discussed the need to consider cultural factors throughout the design process. This is by no means an exhaustive list of instructional design models, but it provides an awareness of the systematic nature of instructional design and lays the groundwork for further study. To learn more about the the models highlighted here and many others, the following resources are helpful, explore the material available on Instructional Design Central (https://www.instructionaldesigncentral.com/ instructionaldesignmodels). 


\subsection{Chapter 8 References}

Tracey, M. W., \& Baaki, J. (2014). Design, designers, and reflectionin-action. In B. Hokanson \& A. Gibbons (Eds.), Design in educational technology: Design thinking, design process, and the design studio (pp. 1 - 14). New York: Springer.

Young, P. A. (2008a). The culture based model: Constructing a model of culture. Educational Technology and Society, 11(2), 107-118.

Young, P. A. (2008b). Integrating culture in the design of ICTs. British Journal of Educational Technology, 39(1), 6-17. doi:10.1111/ j.1467-8535.2007.00699.x 



\section{CHAPTER 9: TECHNOLOGY SELECTION AND INTEGRATION}

Time and money are scarce resources in most educational settings, so decisions about purchasing technology and integrating it into the learning environment require careful consideration. This chapter provides a very brief introduction to a few different perspectives on technology integration. After reading this summary, you are encouraged to read the original articles shown in the reference list to gain a more complete understanding of the complexities of incorporating technology into teaching and learning. 



\section{I The "Media Debate"}

In 1983 Dr. Richard Clark published a literature review (Clark, 1983) where he concluded that "media do not influence learning under any conditions" (p. 445). He believed media were "mere vehicles that deliver instruction but do not influence student achievement any more than the truck that delivers our groceries causes changes in our nutrition" (1983, p. 445). At the time he recommended that researchers stop doing media comparison studies. By media comparison studies Clark meant research that compares whether learning with new technologies (e.g., computers) differs from learning using more traditional methods (e.g., books, pencil, paper, etc.). Instead of studying the medium itself, Clark encouraged researchers to shif their focus to observing attitudes towards computers and the enjoyment of learning with technology.

Ten years later, the journal Educational Technology Research and Development devoted a special issue to a debate between Clark and Robert Kozma (http://robertkozma.com/), who focused more on the future potential of evolving technology and media. Kozma (1994) argued that instead of considering the question settled, researchers should continue to explore ways that media might influence learning, saying, "If there is no relationship between media and learning it may be because we have not yet made one" (p. 7). Clark (1994) maintained his original view, arguing that studies claiming to find benefits from media were confounded by different teaching methods: "Media and their attributes have important influences on the cost or speed of learning but only the use of adequate instructional methods will influence learning" (Clark, 1994, p. 27).

While other researchers took up the debate, and the costs and benefits of technology have shifted as technology tools evolved, the argument has not been definitively resolved in the field. As someone engaged with or interested in the educational technology field, you 
are encouraged to read the original articles (shown in the reference list below) and then reflect on your own view. Do you think media can or does influence learning? Why or why not?

You might also be interested in viewing this AECT "history makers" interview with Richard Clark:

An interactive or media element has been excluded from

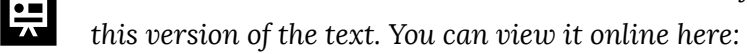

https://open.library.okstate.edu/

foundationsofeducationaltechnology/?p=192

https://youtu.be/

XR6IJrh6pxI?list=PLDD6Hivyl0iMz4Mn1s0aWpCeFJ0JB8DWy $\quad(1: 08$ hours). 


\subsection{Replace, Amplify, and Transform}

Technology in the classroom (face-to-face or online) can serve different purposes. One way to categorize these purposes is the RAT framework (Hughes et al., 2006). The introduction of new technology can lead to the replacement, amplification, or transformation of teaching and learning. Technology as replacement occurs when the new technology provides "different means to the same instructional end" (p. 2). An example of replacement would be a teacher who has students use word processing software to highlight unfamiliar words in a text where they formerly used a highlight marker on a printed page. Amplification refers to increases in efficiency and productivity. For example, when teachers use word processors to prepare and then continuously update teaching materials, or spreadsheet software to track and calculate grades, they are increasing their efficiency and productivity without fundamentally changing the task at hand.

While replacement and amplification are valid reasons to integrate technology into the teaching and learning environment, teachers are also encouraged to look for ways technology might transform what they do. Transformative uses of technology fundamentally change some aspect of the learning process. For example, Hughes et al. (2006) give the example of an English teacher incorporating a writing assignment using hypertext. A hypertext narrative is fundamentally different from a linear narrative in that hypertext incorporates different types of thinking and writing skills, so the technology used in this case can be viewed as transforming the instructional goals and the learning process.

The simplicity of this early taxonomy for classifying technology use is a double-edged sword: it is easy to understand, but risks 
attributing too much power to technology tools rather than how the tools are integrated into the teaching and learning context. The next topic, TPACK, looks at technology integration in a larger context. 


\subsection{TPACK}

The Technological Pedagogical Content Knowledge (TPACK) framework (Mishra \& Koehler, 2006; Koehler, Mishra \& Cain, 2013) is another way of thinking about integrating technology into the teaching and learning process. It builds on earlier work by Lee Shulman (http://www.leeshulman.net/domains/), but adds technology as an additional essential component of teacher knowledge. Koehler, Mishra, and Cain (2013) define the layers of teacher knowledge as follows:

- Content knowledge-knowledge of the subject matter

- Pedagogical knowledge-general knowledge of how students learn and how teachers can facilitate learning

- Pedagogical content knowledge-knowledge of disciplinespecific teaching and learning (e.g., common student misconceptions in the domain and how to overcome them)

- Technology knowledge-knowledge beyond mere computer literacy, encompassing "a deeper, more essential understanding and mastery of information technology for information processing, communication, and problem solving" (p. 15)

- Technological content knowledge-"a deep understanding of the manner in which the subject matter...can be changed by the application of particular technologies" and "which specific technologies are best suited for addressing subject-matter learning" (p. 16)

- Technological pedagogical knowledge-"an understanding of how teaching and learning can change when particular technologies are used in particular ways" (p. 16)

Finally, Technological Pedagogical Content Knowledge (TPACK) is the basis of effective teaching with technology, requiring an 
understanding of the representation of concepts using technologies, pedagogical techniques that use technologies in constructive ways to teach content, knowledge of what makes concepts difficult or easy to learn and how technology can help redress some of the problems that students face, knowledge of students' prior knowledge and theories of epistemology, and knowledge of how technologies can be used to build on existing knowledge to develop new epistemologies or strengthen old ones (p. 16).

For more information on how all of these ideas fit together, see Royce Kimmons' helpful video, "TPACK in Three Minutes" here:
固 An interactive or media element has been excluded from this version of the text. You can view it online here:
https://open.library.okstate.edu/
foundationsofeducationaltechnology/?p=196

https://youtu.be/0wGpSaTzW58 (3:11 minutes).

To dig a little bit deeper, you can view this video featuring one of the TPACK founders, Dr. Punya Mishra:

An interactive or media element has been excluded from this version of the text. You can view it online here:

https://open.library.okstate.edu/ foundationsofeducationaltechnology/?p=196 
https://youtu.be/wn4ElDeZQeM (13:26 minutes).

Note: You will notice that the original article used the acronym "TPCK" and later articles use "TPACK." As the framework evolved the "and" was added to the name simply to make the acronym easier to read and pronounce. 


\subsection{Chapter Summary}

As you can see, there are many perspectives on how and when (and maybe even if!) technology should be integrated into the learning environment. Perspectives range from Clark's $(1983,1994)$ focus on cost and efficiency to the complex interaction of Mishra and Koehler's (2006) TPACK framework. For researchers, technology integration is likely to remain a active area of inquiry in the field for the foreseeable future. For teachers, there will be no easy answers, but your awareness of the complexity of the issue will help you remain a reflective practitioner. 


\subsection{Chapter 9 References}

Clark, R. E. (1983). Reconsidering research on learning from media. Review of Educational Research, 53(4), 445-459.

Clark, R. E. (1994). Media Will Never Influence Learning. Educational Technology Research and Development, 42(2), 21-29.

Hughes, J., Thomas, R., \& Scharber, C. (2006, March). Assessing technology integration: the RAT-replacement, amplification, and transformation - framework. In Society for Information Technology \& Teacher Education International Conference (pp. 1616-1620). Association for the Advancement of Computing in Education (AACE).

Koehler, M., Mishra, P., \& Cain, W. (2013). What is technological pedagogical content knowledge (TPACK)? Journal of Education, 193(3), 13-19.

Kozma, R. (1994). Will media influence learning? Reframing the debate. Educational Technology Research and Development, 42(2), 7-19.

Mishra, P., \& Koehler, M. (2006). Technological pedagogical content knowledge: A framework for teacher knowledge. Teachers College Record, 108, 1017-1054. 



\section{CHAPTER Io: ACCEPTANCE AND DIFFUSION OF TECHNOLOGY}

Educational technologists are often in a position of introducing new technology into the school or workplace. It is therefore important to understand how new technologies and innovations are (or are not) accepted and adopted by the potential users. This chapter will briefly introduce three models of technology acceptance and diffusion: The Technology Acceptance Model, the Decomposed Theory of Planned Behavior, and Diffusion of Innovation. 



\section{Io.I Technology Acceptance Model}

The Technology Acceptance Model (Davis, 1989), or TAM, posits that there are two factors that determine whether a computer system will be accepted by its potential users: (1) perceived usefulness, and (2) perceived ease of use. The key feature of this model is its emphasis on the perceptions of the potential user. That is, while the creator of a given technology product may believe the product is useful and user-friendly, it will not be accepted by its potential users unless the users share those beliefs.

For a quick introduction to TAM, see this 4-minute video:

https://youtu.be/ydIFH1q2NHw. 
This 15-minute video provides more detail on the background of and development of the model: https://youtu.be/Eknh4UbegGw 


\section{Io.2 Decomposed Theory of Planned Behavior}

The Theory of Planned Behavior states that our intentions to perform a certain behavior (such as the adoption of a new technology) arise from three major categories of influence: (1) our attitudes towards the behavior, (2) the influences (norms) of our social circle, and (3) our perceived level of control regarding the behavior. The Decomposed Theory of Planned Behavior builds on the original theory by breaking these three influences into more detailed dimensions. See this five-minute video for a more detailed explanation of the theory:

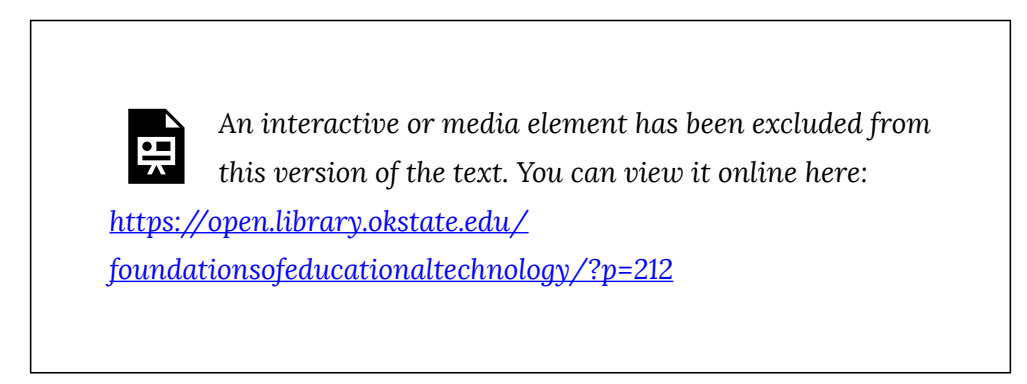

https://youtu.be/DFn-IOcpd8A 


\section{I0.3 Diffusion of Innovation}

In Diffusion of Innovations, Rogers (1995) described how new ideas spread through communities. According to Rogers, there are identifiable characteristics that predict whether and how quickly an innovation will spread through a community.

1. Relative advantage - people are more likely to adopt an innovation if they perceive it as having some advantage over their current situation

2. Compatability - people are more likely to adopt an innovation that fits with their cultural norms, attitudes, and beliefs

3. Complexity - people are more likely to adopt innovations that are easy for them to understand and use

4. Trialability - people are more likely to adopt an innovation if they can test it before committing to its adoption

5. Observability - people are more likely to adopt an innovation if they see others adopt it successfully.

An innovation that has these five characteristics still needs to be communicated to members of the community in order to be adopted. Thus, Rogers identified communication channels as an important element of the diffusion process. With respect to adopting innovation, Rogers believed personal communication between people was more important than mass media communication. Because innovations are not adopted instantly, time is also an important element of Rogers' model. Finally, innovations are communicated over time through a social system.

While innovations diffuse through communities, these communities are made up of individuals making their own decisions about whether to adopt the innovation. Rogers identified five stages in the decision process, as follows: 
1. The knowledge stage, where the individual learns of the existence of the innovation and gathers information about it.

2. The persuasion stage, where the individual actively seeks out knowledge that will help in the decision process

3. The decision stage, where the individual adopts or rejects the innovation

4. The implementation stage, where the individual uses the innovation and evaluates its benefits

5. The confirmation stage, where the individual continues to seek information to confirm that the adoption decision was beneficial.

While these stages are believed to apply to all individuals, of course people vary in their receptivity to new ideas and how much time and information they need to make an adoption decision. Rogers identified the following categories of adopters:

1. Innovators - risk-tolerant people who like to seek out new ideas

2. Early adopters - opinion leaders in the community who are receptive to trying new ideas and have the social position to influence others

3. Early majority - people who are deliberate in their adoption decisions but tend to adopt more quickly than average

4. Late majority - risk-averse people who need to see an innovation being used successfully by others before they adopt it

5. Laggards - the last to adopt an innovation, often only adopting it after a new innovation has already begun to replace it.

Watch the following two videos for a greater understanding of how these groups of adopters operate over time within communication channels in a social structure to spread an innovative idea throughout a community: 
- Part 1

An interactive or media element has been excluded from

믐 this version of the text. You can view it online here:

https://open.library.okstate.edu/

foundationsofeducationaltechnology/?p=214

- https://youtu.be/9QnfWhtujPA

- $\quad$ Part 2

An interactive or media element has been excluded from

글 this version of the text. You can view it online here:

https://open.library.okstate.edu/

foundationsofeducationaltechnology/?p=214

- https://youtu.be/NiNoNYLBabA

While Diffusion of Innovation Theory has played an important role in educational technology research and in the planning of educational technology products, it has, like any theory, been subject to critique. For a critical look at the concept of laggards, see http://www.management.ac.nz/ejrot/cmsconference/2005/ proceedings/technology/Klein.pdf 


\section{Io.4 Chapter Summary}

The theories and models described in this chapter take different perspectives, but all emphasize that the adoption and use of new technology is subject to a variety of influences in a complex interaction. Designers and champions of new technology may not be able to control all of these influences, but understanding them can lead to better implementation and better communication with users. 


\section{I0.5 Chapter io References}

Davis, F. D. (1989). Perceived usefulness, perceived ease of use, and user acceptance of information technology. MIS quarterly, 13(30 319-340.

Rogers, E. M. (1995). Diffusion of innovations. New York, The Free Press. 


\section{CHAPTER II: PROFESSIONAL ETHICS}

The term ethics is defined by Merriam Webster Online as "the discipline dealing with what is good and bad and with moral duty and obligation," and also, in the case of professional ethics, as "the principles of conduct governing an individual or a group" (https://www.merriam-webster.com/dictionary/ethics).

For educational technologists, the Association for Educational Communications and Technology (AECT) publishes standards for ethical practice in the field. In addition, educational technologists in academic settings must adhere to ethical standards when conducting research, and must also maintain academic integrity in their academic work. This chapter addresses all three of these categories of professional ethics.

The AECT Code of Professional Ethics (AECT, 2007) presents principles that "are intended to aid members individually and collectively in maintaining a high level of professional conduct" (preamble). The principles are divided into three categories: commitment to the individual, commitment to society, and commitment to the profession. Commitment to the individual includes promoting diversity and multiple points of view, protecting privacy, and making wise choices in the use of technology for communication and learning. Commitment to society includes behaving with integrity in your workplace and being conscious of the effect of technology on the learning environment. Commitment to the profession includes behaviors such as representing one's skills and education honestly, encouraging diversity of ideas within the profession, and obeying copyright laws. The complete statement of professional ethics can be found at 
http://aect.site-ym.com/members/

group content view.asp?group=91131\&id=309963

You may also be a member of other organizations or professions that have a code of ethics. For example, the Association of American Educators has a code of ethics for teachers (https://www.aaeteachers.org/index.php/about-us/aae-code-ofethics), as does the National Education Association (http://www.nea.org/home/30442.htm). The American Educational Research Association (AERA) has a detailed professional ethics document available on their website at http://www.aera.net/ About-AERA/AERA-Rules-Policies/Professional-Ethics.

It is not unusual for educational technologists to face ethical issues in the workplace. Lin (2007) surveyed instructional design professionals in higher education and found they routinely faced ethical issues in six categories:

- Copyright-communicating with faculty about copyright, obtaining copyright clearance to use specific materials, and maintaining a balance between copyright and educational fair use

- Learner Privacy-protecting student/learner data, including data tracked automatically in learning management systems

- Accessibility-making sure materials are accessible to all learners, and finding ways to resolve the conflict that sometimes arises between accessibility and the implementation of new and innovative technology tools

- Diversity-respecting all learners, avoiding the use of stereotypes in images and other artifacts, and avoiding stereotyping learners (for example, not assuming older learners lack technology skills)

- Conflicts of Interest-avoiding contract work on employer-paid time and respecting the confidentiality of an employer's materials

- Professionalism and Confidence-acquiring and maintaining 
both technical competence and knowledge of learning theory

The strategies that participants in this study reported using to help them navigate these ethical issues included working in teams with diverse expertise, referring to applicable laws for guidance, consulting managers, having a personal sense of right and wrong, and using technical solutions (e.g., passwords) to prevent ethics violations. 



\section{II.I Copyright}

Finding and using digital resources from a variety of sources is integral to the work on an educational technologist, so a solid understanding of copyright is essential. In addition, educational technologist are often called upon to provide guidance to colleagues on copyright issues, and those in a teaching role have a responsibility to help students understand and abide by copyright laws and standards of fair use.

The Oklahoma State University Library provides a concise but thorough summary of copyright laws and fair use standards. Please see the following resources:

Copyright Basics (http://info.library.okstate.edu/ c.php?g=152024\&p=998497)

Fair Use and Exceptions (http://info.library.okstate.edu/ c.php?g=152024\&p=998571)

Links to Other Resources (http://info.library.okstate.edu/ c.php?g=152024\&p=998645)

The Electronic Frontier Foundation provides curriculum to assist teachers in teaching their students about copyright, available at https://www.teachingcopyright.org/.

For more information on how to find usable digital material, see this guide to Creative Commons: https://docs.google.com/document/ d/10QP1R-taLNHpY1K2iaPwJ5s3n-wV1tW3oFTYLNf3F3o/edit. 


\section{II.2 Conflicts of Interest}

A conflict of interest can be defined as "(1) a situation that has the potential to undermine the impartiality of a person because of the possibility of a clash between the person's self-interest and professional interest or public interest, or (2) a situation in which a party's responsibility to a second-party limits its ability to discharge its responsibility to a third-party" (http://www.businessdictionary.com/definition/conflict-ofinterest.html).

In the educational technology field, a conflict of interest can occur in a variety of situations. For example, educational technologists who do freelance consulting work for a technology vendor may have an incentive to convince their primary employer to purchase the consulting company's product, or may have difficulty separating time spent working for the consulting company from time spent on their primary employment. It is important to be aware of these potential conflicts and consider how to avoid them. Also keep in mind that the appearance of conflict of interest may harm your professional reputation even when you are confident you are managing the situation appropriately. 


\section{II.3 Academic Integrity}

Whether writing a paper for a class, submitting a manuscript to a journal, or preparing a presentation in the workplace, care must be taken to avoid plagiarism. While some plagiarism is deliberately committed by those who think they can "get away with" stealing someone else's work, many episodes of plagiarism are accidental and occur as a result of not fully understanding what plagiarism is and how to avoid it. Just like a traffic ticket, however, ignorance of the law does not exempt anyone from the responsibility to follow the law or the consequences of not following it.

Acadia University provides an engaging tutorial with an excellent explanation of what plagiarism is and how you can avoid it in all its forms. You can see the tutorial by following the link below: http://library.acadiau.ca/sites/default/files/library/tutorials/ plagiarism/.

A variety of other resources for learning about and avoiding plagiarism are listed on the OSU library website: http://info.library.okstate.edu/ILS/plagiarism. 


\section{II.4 Ethical Research}

In keeping with federal law and local policy, universities and other research organizations maintain standards for ethical research. These standards include general principles for the responsible conducting of research, and specific rules for the protection of participants in research projects.

\section{Responsible Conduct of Research (RCR)}

According to Oklahoma State University, responsible conduct of research requires attention to topics such as "proper citation of other work, plagiarism, research misconduct, intellectual property and copyright, falsification and unwarranted editing of data, conflict of interest, authorship on manuscripts, and mentor-mentee relationships"

(OSU, n.d.). While RCR is discussed mainly in the context of academic work, these principles apply to educational technologists in all of the roles they may fill, as students, researchers, and practitioners.

Researchers must take care to conduct their research properly, as defined by the standards of their chosen method, and present their findings accurately. They must also treat research participants with respect throughout the process, including data collection, analysis, and reporting of findings.

Another component of RCR is sharing credit appropriately for any publications that result from the research. Generally, everyone who contributes substantially to the project has earned the right to be listed as an author. Conversely, author credit is not "given" to those who do not make substantial contributions. The American 
Psychological Association provides guidelines for authorship that, although written primarily for a graduate student audience, are helpful for all researchers and practitioners in the field of educational technology. These guidelines are available at http://www.apa.org/science/leadership/students/authorshippaper.pdf.

\section{Protection of Human Participants}

Educational technologists frequently perform research with human participants. This is true of academic research and also in some workplace situations, such as usability testing for new educational software or products. Because of past abuses of human subjects, there are federal laws in place to ensure protection of research participants, and universities have Institutional Review Boards (IRB) in place to ensure that these laws are followed. Research done outside of a university setting (e.g., software usability testing) is not subject to IRB oversight, but protection of human volunteers is still important for ethical practice in the field.

University researchers at all levels (faculty, graduate students, etc.) are required to complete training prior to conducting any research with human participants. Information about the IRB process at Oklahoma State University can be found at http://irb.okstate.edu/. 


\section{II.5 Chapter Summary}

Ethics in the educational technology profession encompasses a variety of topics, including, but not limited to, professional competence, copyright, conflicts of interest, academic integrity, and responsible conduct of research. This chapter has provided only a broad overview of important issues to keep in mind as you strive for ethical practice in the field. You should view the information revealed here as a starting place, not as an exhaustive list. As you progress in your career you will want to take advantage of a variety of sources of lifelong learning, such as professional organizations, mentors, trustworthy web resources, and continuing professional education, to help you grow as an ethical educational technology professional. 


\section{II.6 Chapter in References}

AECT (2007). Code of Professional Ethics. Retrieved from http://aect.site-ym.com/members/ group content view.asp?group $=91131 \& i d=309963$

Lin, H. (2007). The ethics of instructional technology: issues and coping strategies experienced by professional technologists in design and training situations in higher education. Educational Technology Research and Development, 55(5), 411-437. doi:10.1007/s11423-006-9029-y

Oklahoma State University (n.d.). Responsible Conduct of Research. Retrieved from https://compliance.okstate.edu/rcr/rcr-index 

This is where you can add appendices or other back matter. 